\title{
DESIGNING OF NOVEL TOPICAL IN SITU POLYMERIC FILM-FORMING SOLUTION SPRAY FORMULATION OF ANTIFUNGAL AGENT: IN VITRO ACTIVITY AND IN VIVO CHARACTERIZATION
}

\author{
NABIL ABDULLAH, AMIT B. PATIL ${ }^{*}$ \\ Department of Pharmaceutics Sciences, JSS College of Pharmacy, Mysuru, JSS Academy of Higher Education and Research, Mysuru, \\ 570015, Karnataka, India \\ Email: nabilalbaheli1987@gmail.com
}

Received: 10 Oct 2021, Revised and Accepted: 12 Nov 2021

\section{ABSTRACT}

Objective: Voriconazole (VCZ) is a broad-spectrum antifungal medication that works by inhibiting fungal Cytochrome P450, preventing fungi growth. The current study aims at developing and characterizing an antifungal in situ film-forming polymeric solution spray containing VCZ for use in topical drug delivery systems.

Methods: Optimized VCZ in situ polymeric film formulation was evaluated for Fourier transform infrared spectroscopy (FTIR), differential scanning calorimeter (DSC), X-ray diffractometry (XRD), Scanning electron microscope (SEM), in vitro and in vivo, ex-vivo investigation using abdominal rat skin and stability studies. The in vivo antifungal activity of the advanced in situ film was examined in albino Wistar rats.

Results: The optimized batch contained 22\% Eudragit RS 100 (ERS) and 4\% Sorbitol. Based on FTIR, XRD, SEM, and rheological studies. Formulation ingredients of VCZ loaded topical in situ polymeric film spray were observed to be compatible and showed no evidence of precipitation, deformation, or discoloration. Diffusion test (in vitro \%), and ex-vivo drug diffusion \% obtained 99.22\%, and 97.45\% respectively. The maximum inhibition zone was measured at $13 \pm 0.07 \mathrm{~mm}$. The Wistar rat was employed as an animal model for skin irritation and antifungal studies. A study of short-term stability observed no significant modifications in the physical properties.

Conclusion: The findings of the optimized VCZ topical in situ polymeric film spray formulation were satisfactory, demonstrating comparable improvement in superficial antifungal treatment.

Keywords: In situ film, Voriconazole, Candida Albicans, In vitro and In vivo antifungal activity

(C) 2022 The Authors. Published by Innovare Academic Sciences Pvt Ltd. This is an open access article under the CC BY license (https://creativecommons.org/licenses/by/4.0/) DOI: https://dx.doi.org/10.22159/ijap.2022v14i1.43581. Journal homepage: https://innovareacademics.in/journals/index.php/ijap

\section{INTRODUCTION}

The fungal kingdom is unbelievably complex, and its representatives can extremely exist in many niches. Astonishingly, despite this outstanding versatility, relatively few human pathogens are found regularly. However, the human immune system can evade fungal infections. As a result, fungi have been considered harmless and seldom designated to be human fungal pathogens until the last two centuries. While some fungi are prime pathogens that cause human disease without a recognized deficiency, the second category of fungi is opportunistic pathogens $[1,2]$.

Polymeric films have proven to be highly effective in topical therapy because they are easy to apply to the skin's surface and retain the medicine for a more extended time by resisting any modification, enhanced cosmetic appearance, including rubbing and washing or wearing clothes $[3,4]$. Polymeric films aid in the avoidance of difficulties or complications with systematically dosed forms and a semi-solid topical formulation. The most identifiable and easily appropriate topical procedure is evolving polymeric film because they produce the desired prolonged outcome while being conveniently and easily topical efficient. In situ polymeric film solution is a novel concept that may evolve unconventional dose methods applied to the skin, such as ointments, creams, gels, patches, and sprays [5-7].

Polymer film solution in situ spray is used in the form of liquid which, after solvent evaporated from their formulation, formed transparent in situ films that adhere to the skin within a very few seconds $[8,9]$. This formulation has four components: an active drug (VCZ), a second-generation triazole (which is used as a model drug), and the polymer (ERS) (which is capable of forming a clear and transparent film at skin temperature upon application), plasticizer as (Sorbitol), and absolute ethanol. However, $3^{2}$ factorial design of the experiment (DoE) is a designed and structured technique; it can be used to determine the relationship between the effect of change in the concentration of the independent variables and its impact on the formulation by establishing a mathematical model $[10,11]$.

This research aims at designing and characterizing antifungal in situ film-forming polymeric solution spray containing VCZ for topical drug delivery. This study mainly focuses on a wider variety of (In vitro, in vivo and Ex-vivo studies), the kinetics of drug release, skin irritation study, antifungal activity, and stability. The study of stability was carried out for six months in our previous study [12], which discussed and analyzed the essential factors, i.e., (solubility for drug and polymer, DSC, FTIR, water vapor permeability (WVP), moister absorption, moisture content, mechanical film properties, spray angle, and spray pattern). Finally, these polymeric filmforming solution sprays F-5 had advantageous characteristics, which could effectively be used as a base method for optimized VCZ in situ film to treat the fungal infections topical drug delivery.

\section{MATERIALS AND METHODS}

\section{Materials}

The required chemicals products have been involved: Voriconazole (Yarrow-chem products Mumbai, India), Eudragit RS100 (ERS) (Vikram Thermo India Ltd Mumbai), Sorbitol (Loba Chemicals laboratory Mumbai), Ethanol (Merck life science PVT. Ltd), and other fine chemicals were purchased locally and from the pharmaceutical laboratory.

\section{Methods}

\section{Preparation of polymeric solution in situ film}

The preparation of Polymeric films has been prepared by dissolving various concentrations of (ERS), ranging from 20 to $24 \%$ in absolute ethanol without plasticizer, and kept for overnight stirring continuously until a clear solution appears, which is followed by the addition of plasticizer with different concentrations, Sorbitol ranging from 2 to $4 \%$. The weighed drug was precisely dissolved in $20 \mathrm{ml}$ of 
the polymeric film solution with constant stirring at $1 \% \mathrm{w} / \mathrm{v}$ concentration in all the formulations $[13,14]$, as shown in table 1 .
For more investigations and studies, the acquired polymer film solution was stored in a spray container at ambient temperature.

Table 1: Composition for optimization of in situ film-forming by DoE

\begin{tabular}{|c|c|c|c|c|c|c|c|c|c|}
\hline \multirow[t]{2}{*}{ Components (\% w/v) } & \multicolumn{9}{|c|}{ Formulations } \\
\hline & F1 & F2 & F3 & F4 & F5 & F6 & F7 & F8 & F9 \\
\hline Voriconazole & 1 & 1 & 1 & 1 & 1 & 1 & 1 & 1 & 1 \\
\hline Eudragit RS100 & 20 & 20 & 20 & 22 & 22 & 22 & 24 & 24 & 24 \\
\hline Sorbitol & 2 & 3 & 2 & 3 & 4 & 4 & 4 & 2 & 3 \\
\hline Ethanol ( $96 \%$ purity) upto (ml) & 20 & & & & & & & & \\
\hline
\end{tabular}

\section{Design of experiment (DoE) to optimize the formulation}

A complete $3^{2}$ design factory was used to optimize formulated in situ polymeric films. The polymer (X1 Eudragit RS100) and plasticizer (X2 sorbitol) concentrations were chosen as independent variables based on the existing related work. In contrast, (Y1) viscosity and (Y2) DT\% as dependent variables were selected and VCZ was a constant value $[15,16]$. A statistical model is concerned with compositional response (degradation) Equation (1).

$$
y=b_{0}+b_{1} x_{2}+b_{3}+b_{4} x^{2} \ldots \ldots \text { (1) }
$$

Where $(\mathrm{Y})$ is the interactive response and $\left(\mathrm{b}_{0}\right)$ is the arithmetical uncaring overreaction of 9 trails. The above interaction in the equation $(\mathrm{Y})$ is the measurable result of preparation ingredients or various autonomous changes $\mathrm{X}$ and $\mathrm{Y}$; b0 is the average arithmetic interaction; b1, b2, and b3 are the correlated coefficients of the elements $\mathrm{X}$ and $\mathrm{Y}$. Factorial design details are provided in table 2. Variables representing each factor were included with an excipient each, with the corresponding qualitative levels. DESIGN EXPERT ${ }^{\circledR}$ (version 10) software brought the optimized formulation.

Table 2: Optimization of in situ film-forming using $3^{2}$ full factorial design

\begin{tabular}{ll}
\hline Variables independent (X1 and X2) & Variables dependent (Y1 and Y2) \\
\hline A: Polymer (Eudragite RS 100) & R1: Viscosity (cps) \\
B: Plasticizer (Sorbitol) & R2: Dry time (s) \\
AB: API & ----- \\
\hline
\end{tabular}

\section{Characterization of polymeric in situ film formulations}

\section{Dry time}

The solution was sprayed on the skin surface and glass slides, allowed to dry, and time (S) was recorded by a digitalized clock. The solution can be allowed to dry in a normal environment, and as a result, the film was formed [17].

\section{Viscosity}

The solutions were measured with a Viscometer of Brookfield (Brookfield-engineering lab. Inc., USA.) at a viscosity $\left(25 \pm 1{ }^{\circ} \mathrm{C}\right) .20$ $\mathrm{ml}$ of the sample was collected in the ULA cylinder, and the ULA S00 spindle was rotated at $10 \mathrm{rpm}$. The torque readings were much higher than $10 \%$. Three measurements were taken, and the average was determined [17].

$$
\mathrm{AL}=\left(\mathrm{w}_{\mathrm{t}}-\mathrm{w}_{0}\right) \cdot \mathrm{Dn}
$$

Where, $A L$-the quantity of the sample given at each distribution, $W t$ after distribution of formula weight, $W 0$-initial formulation weight before distribution, and $D n$-density.

\section{Characterization of optimized polymeric in situ film formulation (F5)}

\section{FTIR spectral study of the drug in situ film}

The polymeric film was crushed using pestle and mortar until powder form was obtained and mixed with Potassium Bromide $(\mathrm{KBr})$ in a 1:5 ratio (Powdered Polymeric film: KBr). With a holder's help, the mixture was pressed to form pellets and placed under an IR beam. Using $\mathrm{KBr}$ pellets, the spectra were read using a wavelength ranging from $400 \mathrm{~cm}^{-1}$ to $4000 \mathrm{~cm}^{-1}[18,19]$.

\section{Differentials scanning calorimetry}

DSC tests were conducted for optimized in situ film formulation using Shimadzu, DSC 60 apparatuses. The polymeric film was grinded in mortar-pestle until a fine powder was formed, then a required less quantity was transferred into sealed aluminum metal pans and scanned at $10{ }^{\circ} \mathrm{C} / \mathrm{min}$ within a range of temperature of 20 ${ }^{\circ} \mathrm{C}-300{ }^{\circ} \mathrm{C}$, and DSC thermogram was recorded. The liquid nitrogen was used as a coolant $[20,21]$.

\section{Scanning electron microscopy}

The microstructure of the films was determined using a scanning electron microscope (JEOL JSM-IT300, Japan). Film samples have been stored for two weeks in an airtight desiccator containing silica gel. Then films were snapped in liquid nitrogen gently and at random smashed to examine the sample's cross-section [23, 24]. Sample film and formulation as a solution was set up on copper stubs, gold-coated, and noted utilizing a step-up voltage of $10 \mathrm{kV}$.

\section{X-ray diffractometry (XRD)}

The XRD analysis of optimized film dried in situ polymeric formulation, pure VCZ, polymer, and the physical mixture was performed at room temperature, and the patterns were obtained using a Rigaku diffractometer. The patterns of diffraction were obtained by Ni-filtered $\mathrm{Cu} \mathrm{K} \alpha$ radiation, where $\lambda=1.498{ }^{\circ} \mathrm{A}$, under $20 \mathrm{~mA}, 40 \mathrm{kV}$ voltage operation [22]. The samples were screened at $10^{\circ}-90^{\circ} 2 \theta$ ranges, with experimental parameters set as scan step size of $0.02^{\circ}$ for 2 seconds with a scan speed of $0.01 \%$ S.

\section{Rheological study}

The rheological performance of optimized polymeric in situ film and placebo formulation solution requires using the MCR100 controlled stress rheometer, having a coaxial cylinder with a radii ratio of 1.08477. The rheometer had a temperature-controlled unit for maintaining the temperature with a precision of $0.01{ }^{\circ} \mathrm{C}$ and a flowing water jacket was a part of the assembly used. The rheological factor, shear stress $(\mathrm{Pa})$ was assessed straightly, rising to a shear rate of $250^{\mathrm{s}-1}$ with a $20-\mathrm{S}$ interval and 25 shear stresses. US200 (Paar-Physica, Anton-Paar Gmbh, Austria) software was used to determine the shear rate. The rheological measurements at three different temperatures levels $\left(4^{\circ} \mathrm{C}, 25^{\circ} \mathrm{C}\right.$, and $\left.37^{\circ} \mathrm{C}\right)$ were carried out corresponding to the storage area and the body temperature, respectively. All experiments were performed in triplicate, with a new sample taken for each assessment [25].

\section{In vitro release study using cellophane membrane}

In vitro diffusion study for the optimized VCZ in situ film solution spray was carried out by a cellophane membrane using Franz diffusion cell. The cellophane membrane was activated by soaking overnight in a phosphate buffer of $\mathrm{pH}$ 6.8. The membrane was kept 
between the donor and receptor compartment. In the donor compartment, $1 \mathrm{ml}$ of polymeric solution was transferred. The receptor compartment had $20 \mathrm{ml}$ of phosphate buffer and the entire surface of the membrane was in contact with it. The sample was withdrawn from the receptor compartment at intervals of $0,15,30$, $60,120,180,240,300,360$, and $420 \mathrm{~min}$. An equal volume of fresh phosphate buffer was added after sample collection each time. The amount of drug diffused was measured by UV spectroscopy at 256 $\mathrm{nm}[26,27]$.

\section{Ex vivo drug diffusion studies}

Franz diffusion methods $\left\{\right.$ an area of $\left.3 \mathrm{~cm}^{2}\right\}$ and receptor volume (25 $\mathrm{ml}$ ) obtained from the skin (abdominal region) of the albino rat were used to study the skin permeation. The Rats were euthanized under anaesthesia, and the hair from the skin was detached entirely. Surgically, the skin from the abdominal piece of the rat was detached multiple times and it was cleaned with saline solution. Rat's skin was freed from the fat and subcutaneous tissue. The excised skin was fitted between two pumps of the Franz diffusion unit on both sides connected with the receptor intermediate and the SC side fronting towards the giver compartment; the optimized formulation weighing $0.1 \mathrm{~g}$ was spread uniformly on the surface skin. The lower compartment of the receptor holds the phosphate buffer $\{\mathrm{pH} 7.4\}$. Dimethyl Sulfoxide $\{2 \% \mathrm{v} / \mathrm{v}\}$ was constantly stimulated with a magnetic agitator and was kept at $37 \pm 1{ }^{\circ} \mathrm{C}$ for a temperature of skins. After the withdrawal of the samples, they were subsequently replaced with the similar phosphate buffer medium via sampling port of the diffusion unit at static time intervals of $0.5,1,2,4,6$, and $7 \mathrm{~h}$. Withdrawn samples were analyzed by UV spectrophotometry [28-31].

\section{Kinetics of drug release}

The ex vivo research based on data on drug released were assembled in many testing types, including zero order, first order, Higuchi's type, and Korsmeyer-Pappas, to assess the kinetics of releasing optimized VCZ in situ polymeric film formulation. The following equations detail the function for each model calculation [32].

$$
\text { Zero-order: } \mathrm{C}=\mathrm{k}_{0 \cdot \mathrm{t}} \ldots \ldots \ldots \text { (3) }
$$

Where: $K_{0}$ is the constant rate of zero-order in concentration units/time, $t$ is time in minutes graph of concentration unit inconstant to time may produce a vertical line, the origin of the axes is intercepted at a slope equal to $K_{0}$.

$$
\begin{gathered}
\text { First-order: } \log c=\log _{0}-k_{t / 2} \ldots \ldots \ldots \ldots \text { (4) } \\
\text { Higuchi Model: } \mathrm{Qt}=\mathrm{k}_{\mathrm{t}} \ldots \ldots \ldots \text { (5) }
\end{gathered}
$$

In situations where: $Q t$ is the time of drug release; $K$ is kinetic constant, and $t$ is time in minutes.

\section{In vitro antifungal activity}

\section{Organism and inoculums}

The evaluation of in vitro antifungal activity of developed film forming spray based in situ film was done against Candida albicans implying agar diffusion method through well diffusion technique. Subcultures of Candida albicans ATCC 90028 were procured from June Enterprises PVT. LTD Navi Mumbai, India.

\section{Well diffusion method}

The configuration of Sabouraud's dextrose agar was examined in $250 \mathrm{ml}$ of a pointed conical flask and was melted in $100 \mathrm{ml}$ of purified water, and the $\mathrm{pH}$ was attuned to 5.6 to be sterilized in a hot air oven at $160{ }^{\circ} \mathrm{C}$ aimed, at a time of $60 \mathrm{~min}$. After the accomplishment of sterilization, the medium was put aside at a chamber temperature of $0.5 \mathrm{ml}$ watery suspension culture in $\mathrm{NaCl}$ $0.9 \%$ to $5 \times 10^{5} \mathrm{CFU} / \mathrm{ml}$ were added to $100 \mathrm{ml}$ of a medium at $47 \pm 2$ ${ }^{\circ} \mathrm{C}$ and employed as a vaccinated layer. The average $(20 \mathrm{ml})$ was transferred into a sterilized Petri dish to get 3-4 mm depth. It was confirmed that the medium layer is unchanging in thickness by employing a Petri dish on a smoothed surface. After settling down the medium of chamber temperature, with the assistance of a disinfected cork borer, cups of each $4 \mathrm{~mm}$ diameter were pierced and taken out from the Petri dish [33]. Sterilized solutions of placebo film (A), negative formulation (B), an optimized topical formulation based in situ film (C) in DMSO were added in respectively marked cups $\{0.1 \mathrm{ml}$ of $0.1 \% \mathrm{w} / \mathrm{v}\}$. The solvent (DMSO) was employed as a negative control, and the whole study procedures were accomplished in sterilized conditions. The Petri dish was at that time nurtured for $24 \mathrm{~h}$ at $37^{\circ} \mathrm{C}$. After incubation, the zone of inhibition was evaluated in triplicate.

\section{In vivo studies}

In vivo research work are vital elements of current formulation and contemporary studies since they supply valuable evidence of effectiveness. Twenty-four adult female albino wistar rats weighing 200 to $250 \mathrm{~g}$ were used in this study. Ethical clearance was received, and all experimental animal protocols were endorsed by the Institutional Animal Ethics Committee (IAEC), JSS College of Pharmacy, Mysuru (Proposal no. 33/2019). The experiments were done according to the guidelines of the Committee for the Purpose of Control and Supervision of Experiments on Animals (CPCSEA). These animals were kept free for a regular diet and water. Before the commencement of the investigation, all rats were acclimatized in wire cages for $12 \mathrm{~h}$ light-dark cycle for seven days to allow them to adapt to the new environment [34].

\section{Skin irritation studies}

Irritation of skin study was done and carried out as per the Organisation for Economic Co-operation and Development (OECD) guidelines, and the study procedures were approved by the IAEC. The current research objectives were to examine any possible irritation occurrences of the topical application of polymeric film on rat skin. The hair on the dorsal side was shaved using an electric clipper and cleaned with alcohol for $4 \mathrm{~h}$ before starting the study [35]. Ten healthy female Wistar albino rats (200-250 g). Divided into three groups as $(n=5)$ :

$1^{\text {st }}$ Group G1: Placebo polymeric in situ film, $2^{\text {nd }}$ Group G2: Optimized VCZ polymeric in situ film, and $3^{\text {rd }}$ Group G3: Negative control.

Formulations were topically applied to the target skin area $(0.25$ $\mathrm{ml} / \mathrm{kg} / \mathrm{d})$. It is used by $(1 \mathrm{ml})$ plastic syringe. After the application, careful clinical observation was made for any clinical signs of itching or redness, dryness, papule, scale formation on the skin for $14 \mathrm{~d}$. The mean marks were shown according to their score of brutality triggered by formulation applications noticed in table 3 .

\section{In vivo antifungal activity}

Experimental procedure (in vivo), which includes the handling, was permitted in the proposal of the Committee of Control and Supervision of Experiments on Animals, No. 33/2019 approved by the (CPCSEA). The study aimed to investigate any symptoms that occurred due to the induction of fungal infection (Candida albicans) and improve the optimized formulation's efficacy. The hair on the dorsal side was shaved with the help of an electric clipper, and Veet cream was applied in this area for 5 min to remove the remaining hair and wiped that area of the skin with wet cotton and cleaned with alcohol, $4 \mathrm{~h}$ before starting the study. Infected 15 healthy female Wistar albino rats (200-250 g) were classified into five collections in every group $(n=5)$ as is illustrated below:

$1^{\text {st }}$ group: Negative control, $2^{\text {nd }}$ group: Placebo polymeric in situ film (not infected by Candida albicans suspension), and $3^{\text {rd }}$ group: Optimized VCZ in situ polymeric film.

The inoculation was performed under general anaesthesia. Around 3 $\mathrm{cm}^{2}$ skins back to the examined rat were cleanly removed using an electric clipper, and they were marked respectively. Candida albicans suspension was adjusted to give $\left(10^{7} \mathrm{CFU} / \mathrm{ml}\right)$ was gently implied to rub the cleaned and shaved skin using a sterile, cottontipped swap till they were cleansed. They were not having any visible fluid applied to their shaved skin by gentle impression with a sterile, cotton-tipped swap until no more visible fluid was observed. After the application of each formulation, the animals were kept individually in separate cages to prevent licking of the skin. Rats were provided with regular food and water and observed for any infection. The application of the drug started after the fungal growth 
was confirmed (5-d). Treatment was administered for $14 \mathrm{~d}$ for infected rats.

Additionally, clinical and microbiological characteristics were examined. These included clinical symptoms such as itching, redness, dryness, papules, and scaling on the skin, as well as the microbial findings include microscopic findings of papules, papulovesicular, scales, crusts [36, 37]. The mean marks were shown according to their score of brutality triggered by formulation applications noticed in table 3 .

Table 3: Description of lesion scores for clinical assessment of animals

\begin{tabular}{lll}
\hline S. No. & Description & Score \\
\hline 1 & None erythema & 0 \\
2 & Minor erythema (scarcely traceable bright pink) & 1 \\
3 & Reasonable erythema (dark pink) & 2 \\
4 & Modest to severe erythema (bright red) & 3 \\
5 & Severe erythema (ultimate redness) & 4 \\
\hline
\end{tabular}

Histopathological examination was done for the skin tissues and organs of G1, G2, and G3 rats. In the last stage, the rats were immediately euthanized and sacrificed by the cervical dislocation method on the $15^{\text {th }}$ day. The treated part of the skin was collected from all the treated groups, and collected samples were sent to histopathological centre Clarette Biotech Private Limited, Mysuru, India.

\section{Stability studies}

The stability analysis is one of the essential planning variables to ensure protection and product adequacy. Meanwhile, it represents a significant advance on forms of improvement. It can show that the essence of the item influenced by various ecological elements changes over time to demonstrate the manufacturing industry potential. Drug degradation or decomposition occurs between the capacity conditions resulting from experimental drug or product instability changes. This could quickly decrease the centralized dosage form of the medicine, so the stability analysis was evaluated. The stability analysis aimed to estimate a product shelf-life by accelerating the degradation rate; in most cases, the temperature and relative humidity $(\mathrm{RH})$ conditions were increased $[38,39]$.

An optimized formulation was kept away from the light for six months. And checked every two months; various measures including viscosity, the volume of solution delivered for every actuation, $\mathrm{pH}$, the angle of spray, spray pattern, and in vitro experiments on drug release were subject to the formulation. The study procedure used was identical to that mentioned previous section. It was necessary to separate the samples for the stability analysis into three different groups and store them in a refrigerator $\left(4 \pm 2^{\circ} \mathrm{C}\right)$, room temperature $\left(25 \pm 2^{\circ} \mathrm{C} / 60 \pm 5 \% \mathrm{RH}\right)$, and humidity control chamber $\left(40 \pm 2^{\circ} \mathrm{C} / 75 \pm 5 \% \mathrm{RH}\right)$.

\section{RESULTS AND DISCUSSION}

\section{Design of experiment (DoE) for VCZ in situ film formulations}

A $3^{2}$-level factorial, for optimization of the formulation, complete factor design was employed. The rate of the independent variables was based on the preliminary results of the batch. For the ERS, the low, medium, and high rates were $20 \%, 22 \%$, and $24 \%$, respectively. Plasticiser was used at low (2\%), medium (3\%), and high (4\%) rates and VCZ was a constant value of $1 \%$. Respectively. Variable effect independently on Y1 viscosity (cps) and DT (s) Y2. Thus, to achieve the formulation with desired Viscosity and DT. Two independent variables were tested in the $3^{2}$-complete factorial design, each at three levels, and experimental trials were performed for all nine possible combinations [40]. The design layout of the $3^{2}$-full factorial design is shown in table 4 . Two independent variables were selected as below:

$\mathrm{X} 1=$ concentration $\% \mathrm{w} / \mathrm{v}$ of ERS.

$\mathrm{X} 2=$ concentration $\% \mathrm{w} / \mathrm{v}$ of Sorbitol.

Table 4: $3^{2}$-full factorial design variables for polymeric film and level code

\begin{tabular}{llll}
\hline Variables of independent & & Variables of dependent & \\
\hline X1 & X2 & Y1 & Y2 \\
\hline Concentration of ERS (\% w/v) & Concentration of Sorbitol (\% w/v) & Viscosity (cps) & Drying time (s) \\
\hline Level coded & X1 (ERS) & X2 (Sorbitol) & \\
Low- $(-1)$ & 20 & 2 \\
Medium- $(0)$ & 22 & 3 \\
High- $(+1)$ & 24 & 4 \\
\hline
\end{tabular}

Based on the experimental design, the factor combinations resulted in nine different polymeric film formulations; as per the suggestion, different polymeric film formulation batches were prepared and then evaluated for both respondents. The responses observed were fit to 9 runs, and it has been noted that the best fit model was a quadratic model for the two dependent variables. The model's significance and the model terms generated were analyzed by analysis of variance (ANOVA).

\section{Characterization of polymeric in situ film formulations}

\section{Drying time}

The polymeric in situ film-forming drying time was determined to ascertain how quickly the film forms once the solution is sprayed. In situations of room temperature, the polymeric solution has been sprayed on the glass slide surface and then allowed it dry at ambient temperature [38]. The drying time was also directly observed after applying the polymeric film-forming solution on the skin (hand-arm), as illustrated in fig. $\{1$ (ii)\}. A glass plate was put against the film formed without being pressed to determine whether the film had dried. This technique represents realistic conditions because the skin has pores and body heat, causing the drying time in the film time drying test to differ from glass plates; additionally, a polymer film solution was applied to the skin of rats, as shown in fig. $\{1$ (i) $\}$. directly observed the drying time. Combinations of factors $\mathrm{A}$ and $\mathrm{B}$ resulted in the different response variables for the DT (R2) based on $3^{2}$ full factorial designs. The equation ANOVA indicated the model $F$ values 760.20 . P-value $<0.0001$, showing the model to be significant. ANOVA for DT conclusion mentioned in table 6 . The reduced model was confounding, but the most important parameters influencing the response were screened.

$$
10.167-0.667 \mathrm{x}_{1}+(-8.833) \mathrm{x}_{2}+0.5 \mathrm{x}^{1}-2 \mathrm{x}^{2} \ldots
$$

The correlation coefficient was respectively 0.995 and 0.993 in the complete model and the reduced form. Increased ERS concentration increased DT requires optimized formulation (Y1) development. The polynomial equation above shows an intense match of response variables at various levels. The predicted vs. actual interaction, 3D response, and Contour plot surface of R2 are shown in fig. 2, which indicated a significant decrease in the drying time with an increase in the concentrations of factors A and B. 
Group type

(i)

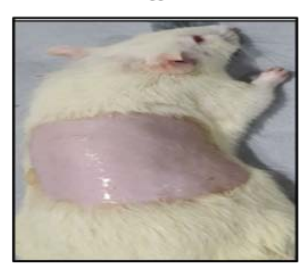

(ii)

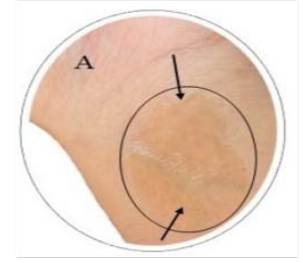

b
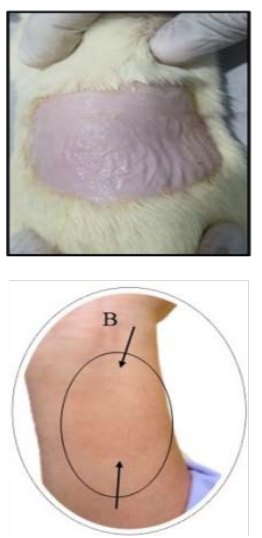

c
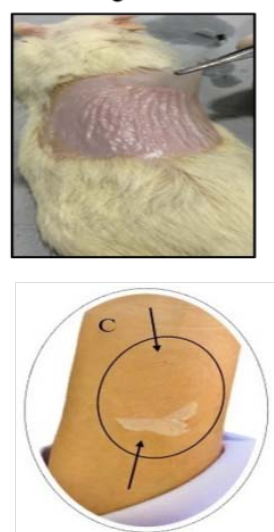

Fig. 1: Photographic images of dry polymeric spray film on (i) Rat's skin and (ii) human arm (a): Spraying of solution (b) Formation of polymeric film and (c): Complete drying of formed polymeric film
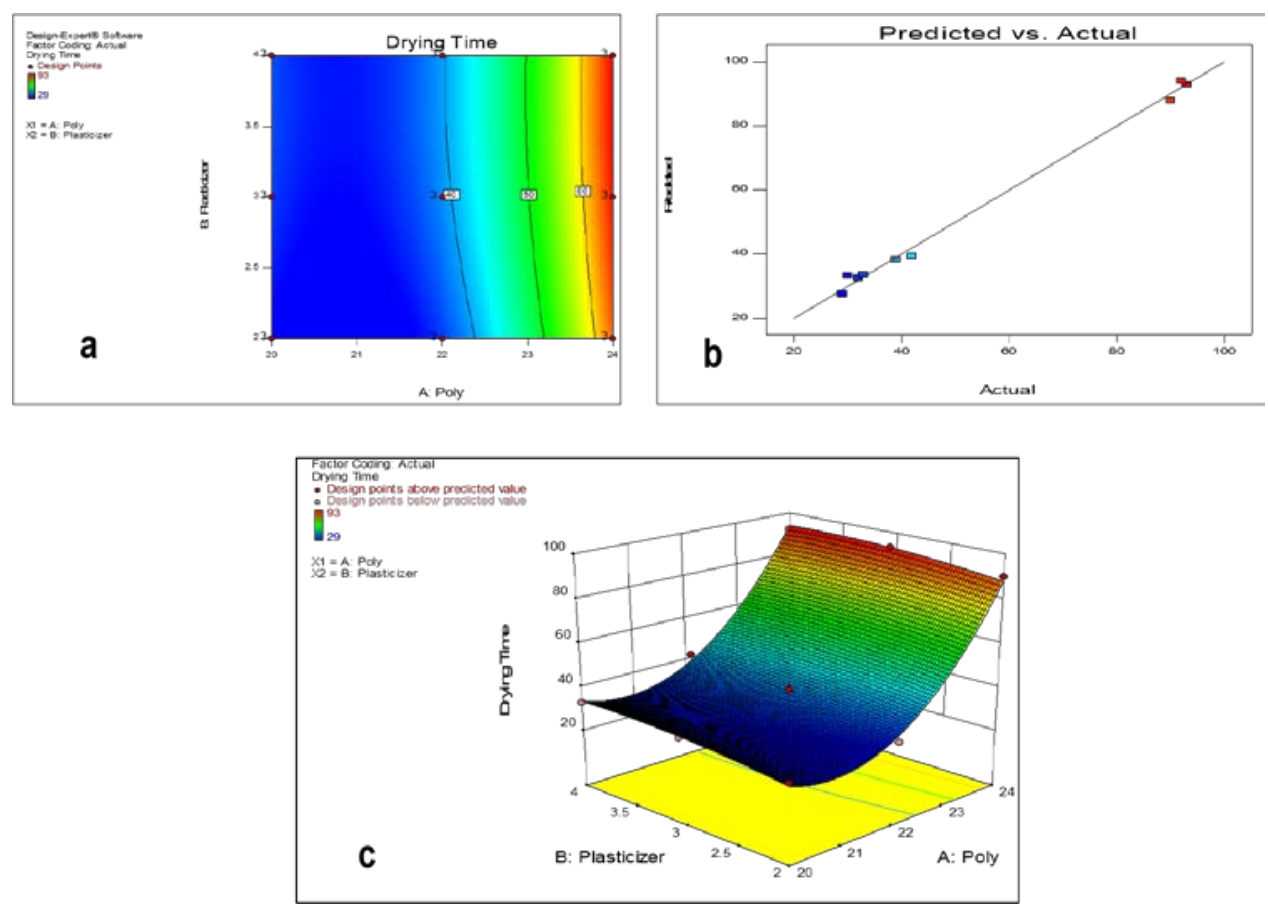

Fig. 2: (a) Response surface plots of R1 DT(s) of VCZ based in situ films (b) Linear difference between occurrence and estimated drying time value (c) Overlay plot for optimization of VCZ based in situ films

Table 5: Various in situ-based variations of the polymeric film with $3^{2}$ (DoE)

\begin{tabular}{lll}
\hline Code of formulations & Responses R1 & \multicolumn{2}{l}{ Responses R2 (DT* $(\mathbf{s}))^{\text {RT }^{\circ} \text { C) }}$} \\
\cline { 2 - 3 } & Viscosity & $29 \pm 0.02$ \\
F1 & $0.12 \pm 0.05$ & $32 \pm 0.02$ \\
F2 & $0.12 \pm 0.07$ & $33 \pm 0.09$ \\
F3 & $0.14 \pm 0.08$ & $30 \pm 0.05$ \\
F4 & $0.13 \pm 0.09$ & $39 \pm 0.06$ \\
F5 & $0.13 \pm 0.04$ & $42 \pm 0.04$ \\
F6 & $0.14 \pm 0.02$ & $90 \pm 0.05$ \\
F7 & $0.19 \pm 0.03$ & $93 \pm 0.07$ \\
F8 & $0.19 \pm 0.01$ & $92 \pm 0.03$ \\
F9 & $0.20 \pm 0.07$ & Medium levels \\
Factor levels of studied & Low levels & 0 \\
A: polymers quantity (\%) & -1 & $30 \pm 0.05$ \\
B: Plasticizer quantity (\%) & 19 & 23 \\
\hline
\end{tabular}

${ }^{*}$ mean $\pm \mathrm{SD} ; \mathrm{n}=3$, RT $\left({ }^{\circ} \mathrm{C}\right)$ : Room Temperature, $\mathrm{BT}\left({ }^{\circ} \mathrm{C}\right)$ : Body Temperature 


\section{Viscosity}

Moderate viscosity is an acceptable flow characteristic of in situ filmforming solutions. High or low viscosity results in non-uniform film production; viscosity is one of the most significant rheological parameters for polymeric in situ film [40]. It affects the use of film and in vivo performance [38]. Viscosity is a significant factor in the time the drug resides in the skin. The viscosity of the polymeric film solution was found at $0.12,0.12,0.14,0.13,0.13,0.14,0.19,0.19$, and 0.20 , respectively. Optimized formulation F5 displayed sufficient viscosity, which revealed a good film property of in situ film for topical application, and they were not highly viscous and easily flowable film. The viscosity profile of formulation F1 to F9 is shown in table 5 . On the basis of $3^{2}$ factorial designs, the combinations of factors $A$ and $B$ have resulted in the different response variables for the viscosity (R1). The equation ANOVA indicated the model $F$ values 42.97. P-value $<0.00001$, showing the significant model. ANOVA for viscosity (R1) conclusion is mentioned in table 6 . The reduced model was confounding, but the most important parameters influencing the response were screened.

$$
2.44-0.23 x_{1}+0.00+x_{2}+0.01+x^{1}-2 x^{2}
$$

Table 6: ANOVA of dry time \% and viscosity (cps) responses (DoE)

\begin{tabular}{|c|c|c|c|c|c|c|c|c|}
\hline S. No. & Response & Source & Sum of squares & df & Mean square & Value (F) & Value (P) & Conclusion \\
\hline \multirow[t]{5}{*}{1} & \multirow[t]{5}{*}{ Dry time \% } & Model & 20168.00 & 4 & 5042.00 & 1260.50 & $<0.0001$ & $\uparrow$ \\
\hline & & A-Polymer & 16380.50 & 1 & 16380.50 & 4095.13 & $<0.0001$ & Significant \\
\hline & & B-Plasticizer & 162.00 & 1 & 162.00 & 40.50 & $<0.0001$ & $\uparrow$ \\
\hline & & Residual & 88.00 & 22 & 4.00 & - & - & \\
\hline & & Cor Total & 20256 & 26 & - & - & - & \\
\hline \multirow[t]{5}{*}{2} & \multirow{5}{*}{$\begin{array}{l}\text { Viscosity } \\
\text { (cps) }\end{array}$} & Model & 0.025 & 5 & 4.961 .3 & 760.20 & $<0.0001$ & $\uparrow$ \\
\hline & & A-Polymer & 0.019 & 1 & 0.019 & 2963.55 & $<0.0001$ & Significant \\
\hline & & B-Plasticizer & 6.722 .4 & 1 & 6.722 .4 & 103.01 & $<0.0001$ & $\uparrow$ \\
\hline & & Residual & 1.370 .4 & 21 & 6.526 .6 & - & - & \\
\hline & & Cor Total & 0.025 & 26 & - & - & - & \\
\hline
\end{tabular}

The correlation coefficient was 0.854 in the complete model and reduced form. The polynomial equation above shows an intense match of response variables at various levels. The predicted vs. actual interaction, 3D response, and contour plot surface of R1 are shown in fig. 3, which indicated a significant increase in the viscosity (R1). With an increase in the concentrations of components A and B.

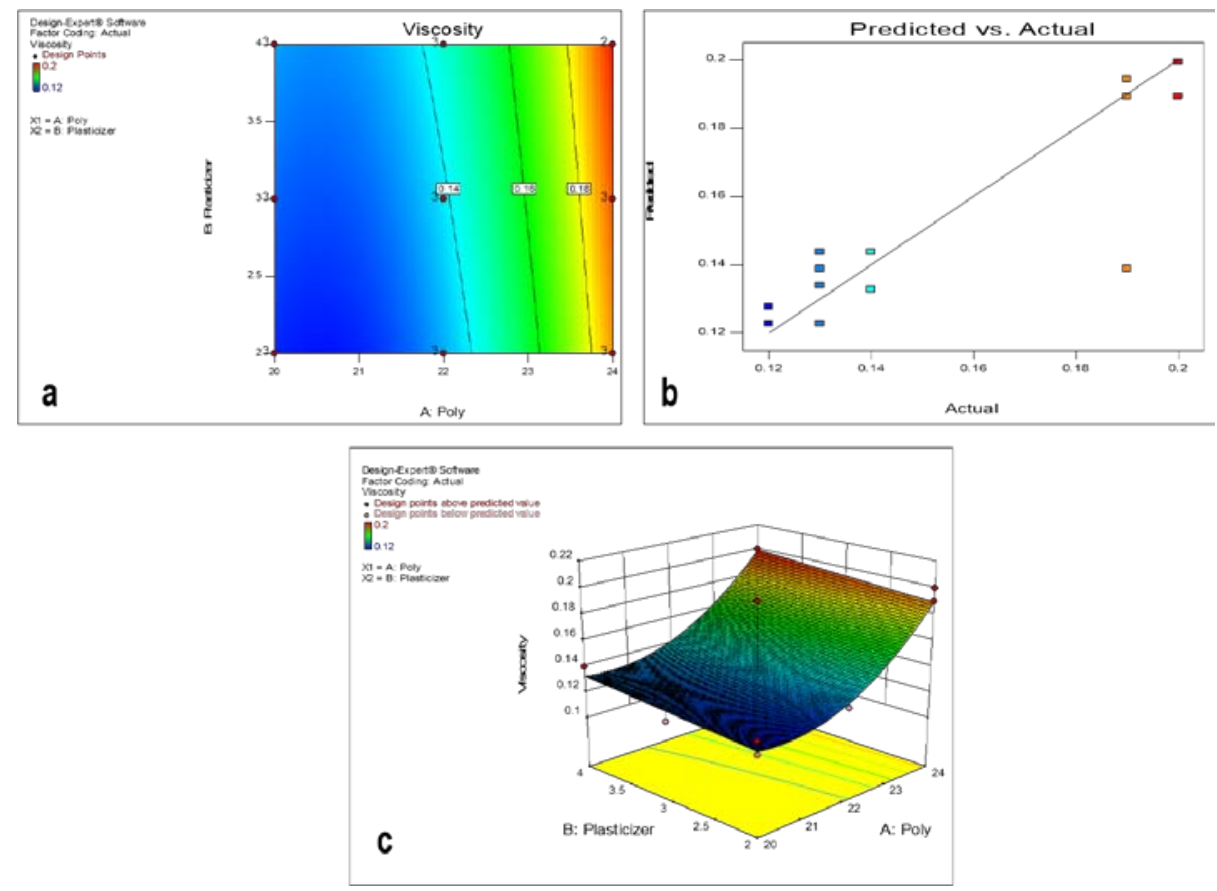

Fig. 3: (a) Response surface plots of R1 Viscosity (cps) of VCZ based in situ film Formulation (b) Linear difference between occurrence and estimated viscosity value (c) Overlay plot viscosity on VCZ dependent in situ film formulation

Characterization of optimized polymeric in situ film formulation (F5)

\section{FTIR spectral study}

FT-IR spectroscopy was employed to obtain conformational information about the film-forming. It was used to investigate the interactions between polymer ERS, drug VCZ, and their physical mixture; the $\mathrm{OH}$ range VCZ of FTIR generally demonstrates absorption peaks around 3200, 3046, and $1090 \mathrm{~cm}-1$, which are attributed to the stretching vibrations of $\mathrm{OH}, \mathrm{CH}$, and $\mathrm{CO}$, respectively. The VCZ powder exhibited absorption peaks at 3200 $\mathrm{cm}-1$, which corresponded to the stretching vibrations of $\mathrm{OH}$. Bands at $3100-2850,1670-1390$, and $1360-1250 \mathrm{~cm}-1$ were assigned to the alkane $\mathrm{CH}, \mathrm{C}=\mathrm{C}$ aromatic, and aryl $\mathrm{C}-\mathrm{N}$ stretches. In a physical mixture of VCZ and ERS, the spectrum of the physical mixture of VCZ and ERS was identical. There is no presence or disappearance of VCZ peaks of the same characteristics as those listed in table 7 and verified by the lack of chemical interactions between VCZ and ERS. From the results, the compatibility of VCZ and the selected polymer were concluded in fig. 4 . 


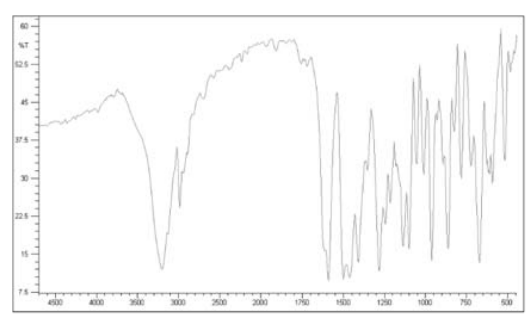

a

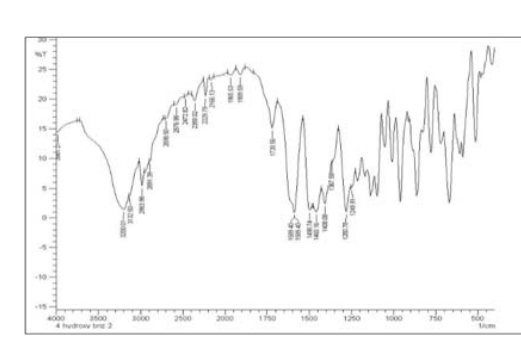

C

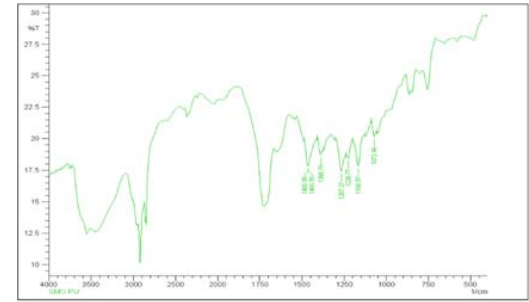

b

Fig. 4: FTIR-Spectra of (a) Pure VCZ (b) Pure ERS (c) Physical mixture (VCZ+ERS)

Table 7: Functional groups and identify FT-IR Spectral of pure VCZ and physical mixture

\begin{tabular}{lll}
\hline Functional group & Frequency of drug $\mathbf{( c m}-\mathbf{1})$ & Voriconazole+Eudragite RS100 \\
\cline { 2 - 3 } & Voriconazole & 1671.31 \\
C=N (Stretch) & 1670.09 & 1299.23 \\
C-H aryl halides & 1290.34 & 1397.12 \\
C-C Stretching of aromatics & 1390.40 & 3098.24 \\
C=H stretching aromatics & 3100.54 & 3199.41 \\
O=H Stretching of alcohols & 3200.08 & 1599.22 \\
C=C (Stretch) & 1590.12 & \\
\hline
\end{tabular}

\section{Differential scanning calorimetry (DSC)}

Table 8 and fig. 5 show the respective VCZ DSC thermograms and their physical mixture (VCZ with ERS). VCZ thermogram displayed a wide sharp endothermic at $138.07{ }^{\circ} \mathrm{C}$, which was related to the evolution of moisture of the sample. The prominent melting peak at $182.91{ }^{\circ} \mathrm{C}$ manifested the natural crystalline state of polymer (ERS). In a physical mixture, the characteristic endothermic peaks of both drug and polymer were observed original authentic locations. VCZ had almost no interaction with the polymer.

Table 8: DSC data of VCZ+ERS100

\begin{tabular}{lllll}
\hline S. No. & Thermal analysis & To $\left.{ }^{\circ} \mathbf{C}\right)$ & $\mathbf{T}_{\mathbf{m}\left({ }^{\circ} \mathbf{C}\right)}$ & $\mathbf{T}_{\mathbf{c}\left({ }^{\circ} \mathbf{C}\right)}$ \\
\hline 1 & Voriconazole & $130.95 \mathrm{c}$ & $133.67 \mathrm{c}$ & 138.67 \\
2 & Eudragite RS100 & 177.69 & 186.66 & 7.72 \\
3 & Voriconazole+Eudragite RS100 & 129.35 & 133.63 & 8.24 \\
\hline
\end{tabular}

$\mathrm{T} \circ$ - melt begins, $\mathrm{T}_{\mathrm{m}}$-melting point, $\mathrm{T}_{\mathrm{c}}$-melting completion, $\mathrm{DSC}$ data collected at $10^{\circ} \mathrm{C} / \mathrm{min}$.

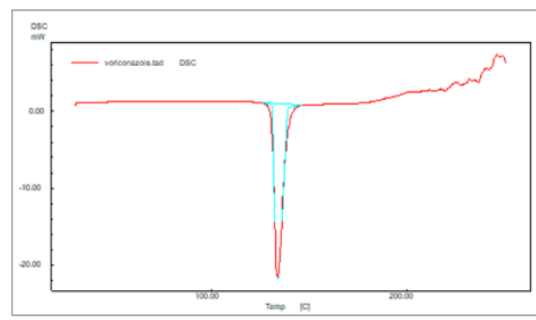

a

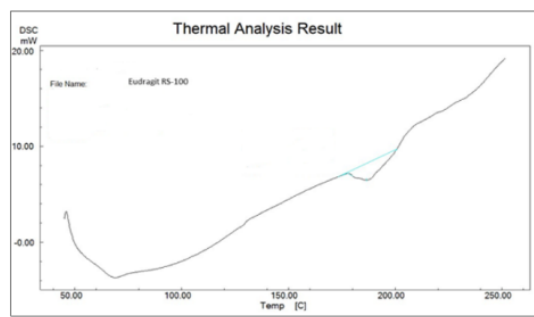

b

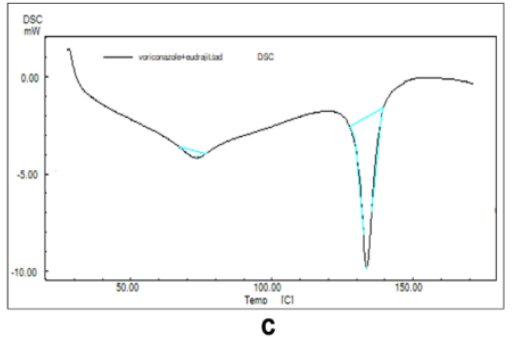

Fig. 5: DSC of (a) Pure VCZ (b) Eudragite RS 100 (c) Physical combination (VCZ with ERS) 


\section{Scanning electron microscopy}

Morphological investigation of VCZ in situ film-forming optimized formulation (F-5) and Placebo in situ film-forming formulation (film dried) were carried out with the help of scanning electron microscopy (SEM). SEM images were illustrated in fig. 6 and showed that prepared in situ films of optimized formulation were spherical with a smooth surface. Particulate aggregation was not observed, and results were in good agreement with particle size analysis results. No residual, intact crystals of VCZ were detected on the in situ film surface, establishing that the in situ film matrix was entirely formed by VCZ and ERS 100 .
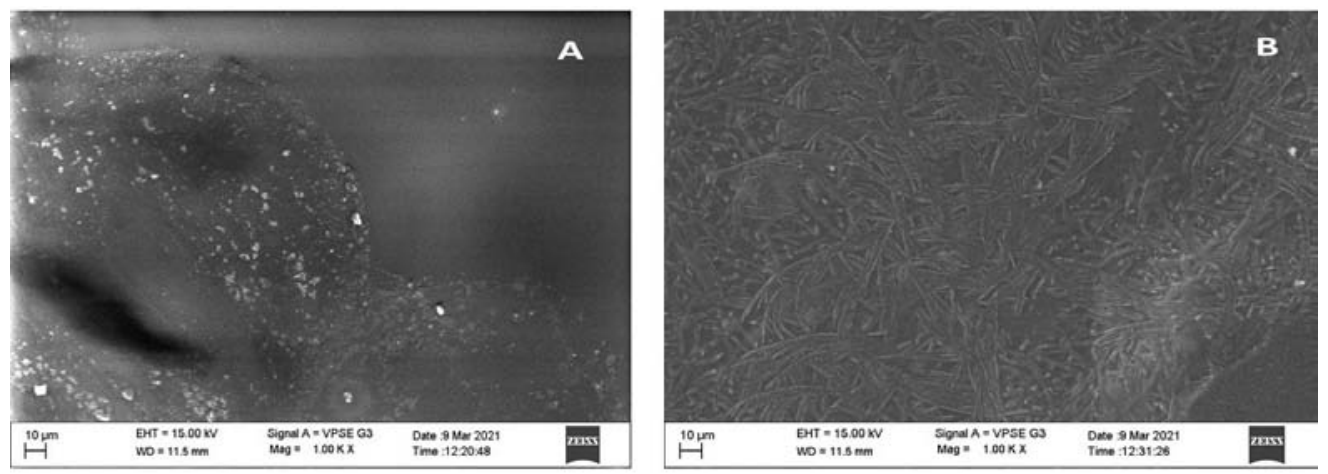

Fig. 6: Scanned images of the blank polymeric film (A) and VCZ loaded polymeric film (B) displaying the surface morphology

\section{X-ray diffractometry}

The crystalline character of pure VCZ, ERS, physical mixture, and in situ film dried was evaluated using X-ray diffraction, as illustrated in fig. 7. A sharp peak of the VCZ with high intensity was observed at $13.5^{\circ}, 14.6^{\circ}, 17.4^{\circ}, 18.7^{\circ}$, and $21.2^{\circ}$ angles. i.e., XRD of the pure VCZ. This indicated that the VCZ was crystalline. The ERS showed peaks at $12.13^{\circ}, 13.45^{\circ}, 14.20^{\circ}, 19.30^{\circ}, 21.14^{\circ}$, and $27.1^{\circ} \theta$. XRD physical mixture of VCZ and ERS produced a less crystalline form with exhibited peaks at $5.2^{\circ}, 14.52^{\circ}$, and $20.28^{\circ}$. In situ film dried containing VCZ showed peaks at $12.13^{\circ}, 13.45^{\circ}, 14.20^{\circ}, 19.30^{\circ}$, $21.14^{\circ}, 27.1^{\circ}$. In situ film-forming exhibited a diminished VCZ peak, which means the ERS might contain dissolved VCZ in the molecularly dispersed form. The peaks of the ERS did not show any significant change. This indicated that the VCZ is entrapped in the ERS shell, gaining an amorphous nature.

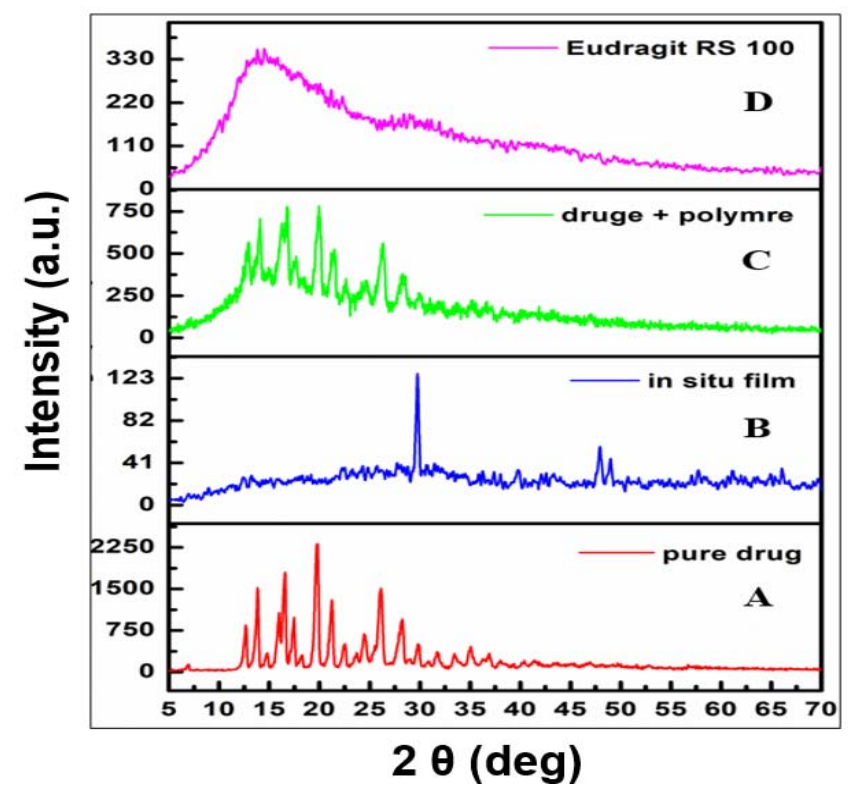

Fig. 7: XRD spectra of a. Pure VCZ, b. film dried in situ films, c. Physical mixture of VCZ with ERS d. Pure ERS

\section{Rheological study}

The purpose of flow testing is to determine whether a compound is thixotropic or not. If a mixture has these flow characteristics, it will pass through the sprayer nozzle repeatedly. The following property makes the film-forming solution being thinner as it passes through the nozzle (stressed) and returns to its initial viscosity when sprayed (stress is lost). For any formulation, it is important to test their rheological behavior for topical applications of drug delivery. For its effectiveness, the delivery of molecules in or through the skin is essential. The acceptable film- forming solution flow characteristic is moderate viscosity, as high or low viscosity contributes to non-uniform film production [39]. The relationship among the shear stress and shear rate can be explained by the Ostwald-de Waele model or power-law equation as mentioned below:

$$
\sigma=\mathrm{K} \times \gamma^{\mathrm{n}}
$$

Where $\sigma$ Indicates the shear stress $(\mathrm{Pa}), K$ indicates the consistency index $\left(\mathrm{Pa} \mathrm{s}^{\mathrm{n}}\right), \gamma$ Indicates the shear rate $\left(\mathrm{s}^{-1}\right)$, and $\mathrm{n}$ indicates the flow behavior index. 
If the fluid is Newtonian in nature, $n=1$. Hence, $K$ becomes the viscosity $\eta$ (Pa s) of the fluid. Rheological studies of optimized VCZ in situ filmforming solution and placebo were performed to study the effect of polymer proportion on the viscosity. The rheograms at $4{ }^{\circ} \mathrm{C}, 25^{\circ} \mathrm{C}$, and $37^{\circ} \mathrm{C}$ have shown a linear increase in shear stress with increasing shear rate amid a line passing through the origin. Thereby, this indicates the Newtonian nature of the flow type mentioned in table 9. (The optimized formulation in fig. $\{9$ (i) $\}$ and Placebo formulation in fig. $\{9$ (ii) $\}$ ).

Table 9: Noticing for rheological analysis of placebo and optimized VCZ based topical in situ film

\begin{tabular}{|c|c|c|c|c|}
\hline Temperature & Flow type & $\eta(\mathrm{Pa}) / \mathrm{k}\left(\mathrm{Pa}^{\mathrm{n}}\right)$ & $\mathbf{n}$ & $\mathbf{R}$ \\
\hline \multicolumn{5}{|c|}{ Placebo in situ film } \\
\hline $4^{\circ} \mathrm{C}$ & Newtonian & 0.9225 & 000 & 0.9999 \\
\hline $25^{\circ} \mathrm{C}$ & Newtonian & 0.5775 & 000 & 1 \\
\hline $37^{\circ} \mathrm{C}$ & Newtonian & 0.5508 & 000 & 0.998 \\
\hline \multicolumn{5}{|c|}{ Optimized voriconazole based topical in situ film } \\
\hline $4{ }^{\circ} \mathrm{C}$ & Newtonian & 0.58675 & 000 & 1 \\
\hline $25^{\circ} \mathrm{C}$ & Newtonian & 0.52779 & 000 & 0.9999 \\
\hline $37^{\circ} \mathrm{C}$ & Newtonian & 0.51572 & 000 & 0.9993 \\
\hline
\end{tabular}

For the Newtonian flow-type, ${ }^{*} \mathrm{n}$ is always 1

(i)

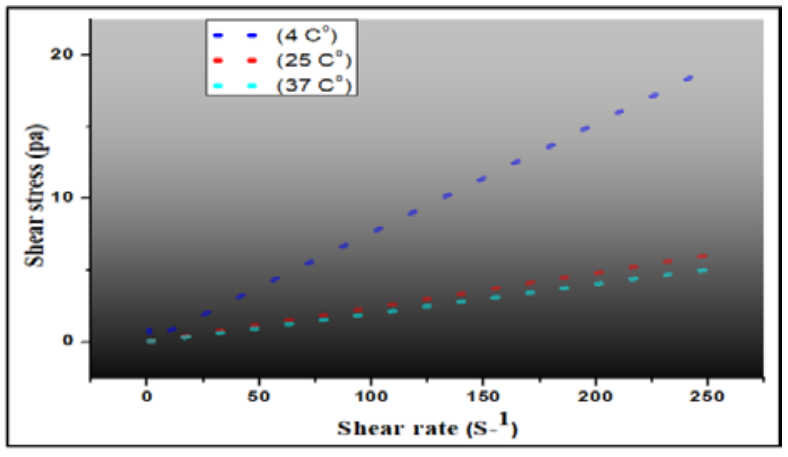

(ii)

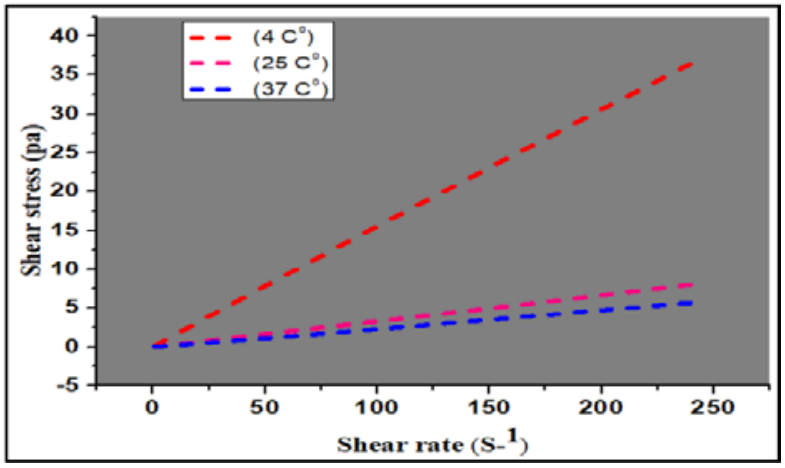

Fig. 9: Rheograms images of (i) placebo polymeric in situ film at $4{ }^{\circ} \mathrm{C}$ (Blue line), $25^{\circ} \mathrm{C}$ (Redline), $37^{\circ} \mathrm{C}$ (Cyan line), and (ii) 0 ptimized VCZ based topical in situ film at $\left(4^{\circ} \mathrm{C}\right.$ Redline), $\left(25^{\circ} \mathrm{C}\right.$ Pink lines), $\left(37^{\circ} \mathrm{C}\right.$ Blue line)

\section{In vitro release review of cellophane membrane}

Studies of the drug release were performed in vitro using a cellophane membrane in a Franz diffusion cell. It includes a donor cell and a receiver compartment. The receptor compartment was filled in as a diffusion medium with $20 \mathrm{ml}$ of phosphate buffer $\mathrm{pH} 7.5$ solutions. In the receptor compartment, the prepared polymer solution was a spray, magnetic beads were used to stir the liquid constantly at $50 \mathrm{rpm}$, and $37 \pm 1^{\circ} \mathrm{C}$ held its temperature. $2 \mathrm{ml}$ receptor fluid sample was withdrawn at fixed intervals. The same amount of $2 \mathrm{ml}$ phosphate buffer solution was replaced with the samples measuring their absorbance at $256 \mathrm{~nm}$. The total volume of drug release transported in a formulation containing $22 \%$ of ERS and $1 \%$ of VCZ was $99.33 \pm 0.07$ percent measured from the slope of the linear portion of the curve in table 10 and fig. 10.

Table 10: Absorbance values of in vitro release study

\begin{tabular}{llll}
\hline S. No. & Time (min) & Absorbance & CDR \% \\
\hline 1 & 0 & 0 & 0 \\
2 & 15 & $0.152 \pm 0.05$ & 7.13 \\
3 & 30 & $0.197 \pm 0.02$ & 18.21 \\
4 & 60 & $0.243 \pm 0.01$ & 29.11 \\
5 & 120 & $0.287 \pm 0.05$ & 37.10 \\
6 & 180 & $0.361 \pm 0.09$ & 45.41 \\
7 & 240 & $0.433 \pm 0.02$ & 56.23 \\
8 & 300 & $0.519 \pm 0.04$ & 68.11 \\
9 & 360 & $0.623 \pm 0.04$ & 89.99 \\
10 & 420 & $0.673 \pm 0.05$ & 99.33. \\
\hline
\end{tabular}

Mean value $( \pm S D) n=3$ 


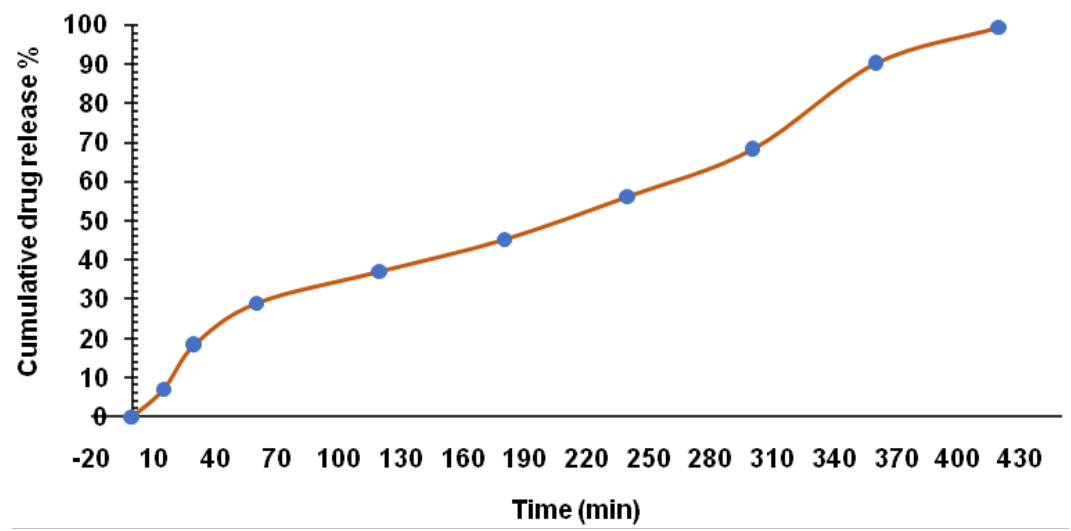

Fig. 10: In vitro diffusion cell using cellophane membrane

\section{Ex-vivo drug diffusion studies}

In situ topical polymeric film formulation F-5 was chosen to study Ex-vivo permeation because it provided the best release among all other formulations in an in vitro drug release study. The dffusion studies from the optimized formulation F5 were performed out over 7 h. Because of its ex vivo similarity to human skin [41, 42]. Rat abdominal skin was used as an animal model skin. The sample obtained was analyzed by a UV spectrophotometer at $258 \mathrm{~nm}$. Table 11 and fig. 11 show the release pattern of optimized formulation F5. The formulation F-5 exhibited a significantly high penetration of VCZ in situ polymeric film. The total amount of VCZ in situ polymeric film transported was found to have a cumulative drug release \% of $97.02 \%$.

Table 11: Cumulative percentage values of ex vivo VCZ in situ film formulation F-5 release study

\begin{tabular}{llll}
\hline S. No. & Time (min) & Absorbance & \%CDR \\
\hline 1 & 0 & 0 & 0 \\
2 & 15 & $0.152 \pm 0.05$ & 5.14 \\
3 & 30 & $0.197 \pm 0.02$ & 39.3 \\
4 & 60 & $0.243 \pm 0.01$ & 38.9 \\
5 & 120 & $0.287 \pm 0.05$ & 45.3 \\
6 & 180 & $0.361 \pm 0.09$ & 55.97 \\
7 & 240 & $0.433 \pm 0.02$ & 66.42 \\
8 & 300 & $0.519 \pm 0.04$ & 78.99 \\
9 & 360 & $0.623 \pm 0.04$ & 93.99 \\
\end{tabular}

${ }^{*}$ Mean of 6 reading \pm SD

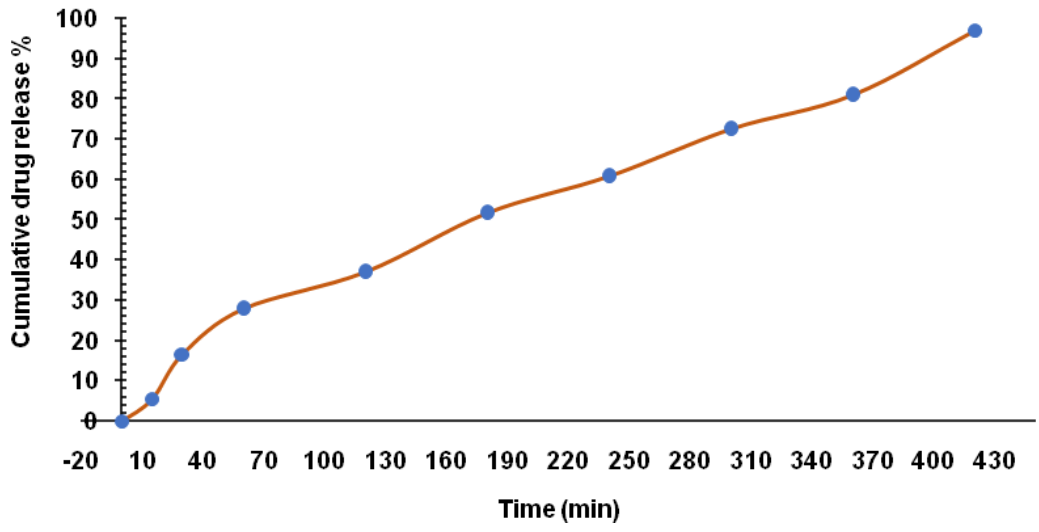

Fig. 11: Ex vivo CDR of VCZ in situ film forming formulation (F5)

\section{Kinetics data analysis}

Ex vivo kinetics studies of VCZ in situ polymeric film transport data of optimized formulation were added analyzed. The model fit-up was carried out using internally built software from the excel sheet program (table 12). The cumulative percentage of VCZ permeated from in situ polymeric film via rat skin was obtained by plotting against time. It was confirmed to kinetics model (Zero-order; first order, Higuchi and Korsmeyer-Pappas) [43]. The best fit model was chosen based on the relatively high correlation coefficient and the correlation value, as described in table 13 . A higher R2 value lowers fisher's rates were observed ( 0.9892 and 0.308 , respectively). The result showed that the drug release of optimized VCZ in situ polymeric film follows the First order model, indicating the mechanism of drug release. It was more than 0.9892 multiple linear regression coefficient data for correlation of data noticed in fig. 12 . 
Table 12: Diffusion data of optimized VCZ In situ film for ex vivo CDR kinetics

\begin{tabular}{|c|c|c|c|c|c|c|}
\hline Time (h) & Log time & SQRT time & \% Cumul. release & Log \% release & \% Drug remaining & Log \% drug remaining \\
\hline 0 & & 0 & 0 & & 100 & 2 \\
\hline 0.25 & -0.602 & 0.500 & 7.76 & 0.890 & 92.24 & 1.965 \\
\hline 0.5 & -0.301 & 0.707 & 17.63 & 1.2463 & 82.37 & 1.916 \\
\hline 1 & 0.000 & 0.000 & 29.71 & 1.4729 & 70.29 & 1.847 \\
\hline 2 & 0.301 & 1.414 & 33.73 & 1.5280 & 66.27 & 1.821 \\
\hline 3 & 0.477 & 1.732 & 51.48 & 1.7116 & 48.52 & 1.686 \\
\hline 4 & 0.602 & 2.000 & 67.02 & 1.8262 & 32.98 & 1.518 \\
\hline 5 & 0.699 & 2.236 & 67.94 & 1.8321 & 32.06 & 1.506 \\
\hline 6 & 0.000 & 2.449 & 79.1 & 0.0000 & 20.9 & 1.320 \\
\hline 7 & 0.000 & 2.646 & 97.02 & 0.0000 & 2.98 & 0.474 \\
\hline
\end{tabular}

Table 13: Release kinetic fitting models for optimized VCZ In situ film

\begin{tabular}{llll}
\hline S. No. & Release kinetic fitting models & Slop & Correlation \\
\hline 1 & Zero order & 12.349 & 0.0443 \\
2 & First order & 0.9953 & 0.0884 \\
3 & Higuchi & $\#$ & 1.323 \\
4 & Korsmeyer-Pappas & 1.312 & 0.9731 \\
\hline
\end{tabular}

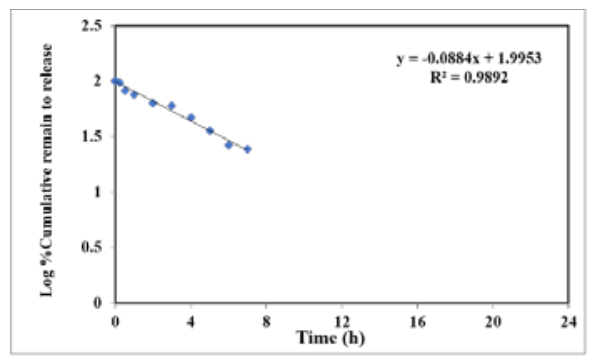

a

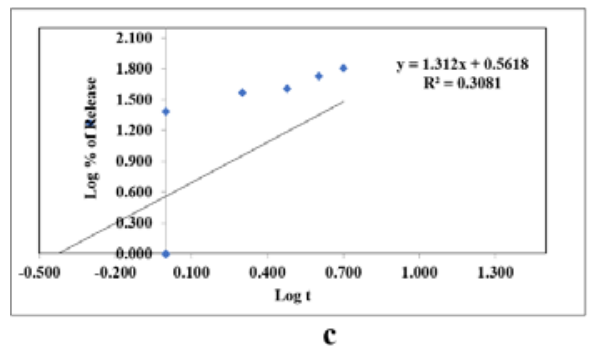

c
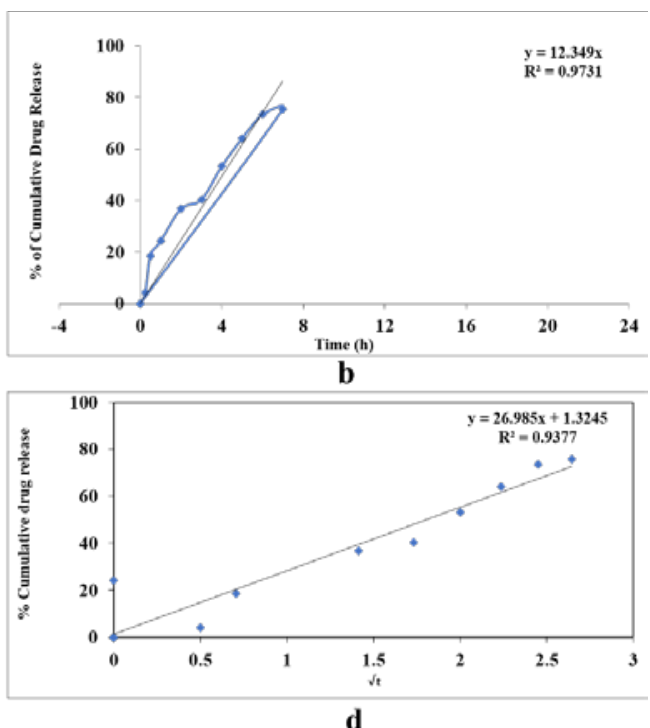

Fig. 12: Kinetic release of (a) Best fitted release kinetic first-order model for optimized VCZ in situ polymeric film, (b) Zero-order plot for optimized VCZ in situ polymeric film, (c) Peppas release model for optimized VCZ in situ polymeric film, (d) Higuchi model for optimized VCZ in situ polymeric film

\section{In vitro antifungal activity}

The in vitro antifungal activities of optimized VCZ based in situ polymeric film formulation F-5 were assayed against fungal strains such as Candida albicans. An experiment was tested microbiologically by the effective diffusion technique. Zone of inhibition was not formed by negative control used DMSO, while placebo in situ polymeric film was $1(\mathrm{~mm})$ due to the alcohol's existence. And while the distinct and clear zone of inhibition was noticed in the case of optimized VCZ-based in situ polymeric film formulation F-5, as shown in table 14 and fig. 13 . VCZ in situ polymeric film results was satisfactory and more efficient for antifungal potential (Candida albicans).

Table 14: Zone of inhibition of in situ films against Candida albicans

\begin{tabular}{lll}
\hline S. No. & Test sample code & Zone of inhibition against Candida albicans (mm) \\
\hline 1 & (C) Negative control & 00 \\
2 & (B) Placebo in situ film & $1 \pm 0.05$ \\
3 & (V) Optimized VCZ in situ film & $13 \pm 0.07$ \\
\hline
\end{tabular}

${ }^{*}$ mean \pm SD, $\mathrm{n}=3$

\section{In vivo studies}

\section{Skin irritation studies}

A skin irritation study on rats' skin was performed to confirm the safety of optimized VCZ in situ polymeric film spray formulation. The irritation potential of the topical formulation was evaluated. According to the findings of this investigation, optimized VCZ in situ polymeric film spray formulation F5 did not cause substantial irritation (erythema, edema, itching, redness, dryness, papule, and scale) or inflammation on or around the site of application on rat skin for up to $14 \mathrm{~d}$. In short, there 
were no apparent signs of skin irritation (erythema and edema) observed on visual observation of skin specimens treated with VCZ loaded in situ polymeric film formulation indicating the absence of any skin irritation. Fig. 14 demonstrates the findings.

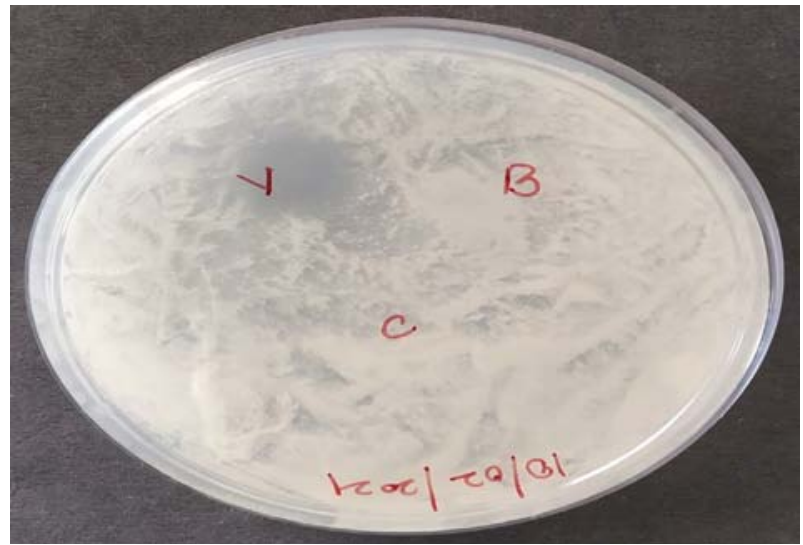

Fig. 13: Image for a zone of inhibition of (C) Negative control, (V) Optimised in situ polymeric film formulation F-5 against Candida albicans, and (B) Placebo in situ polymeric

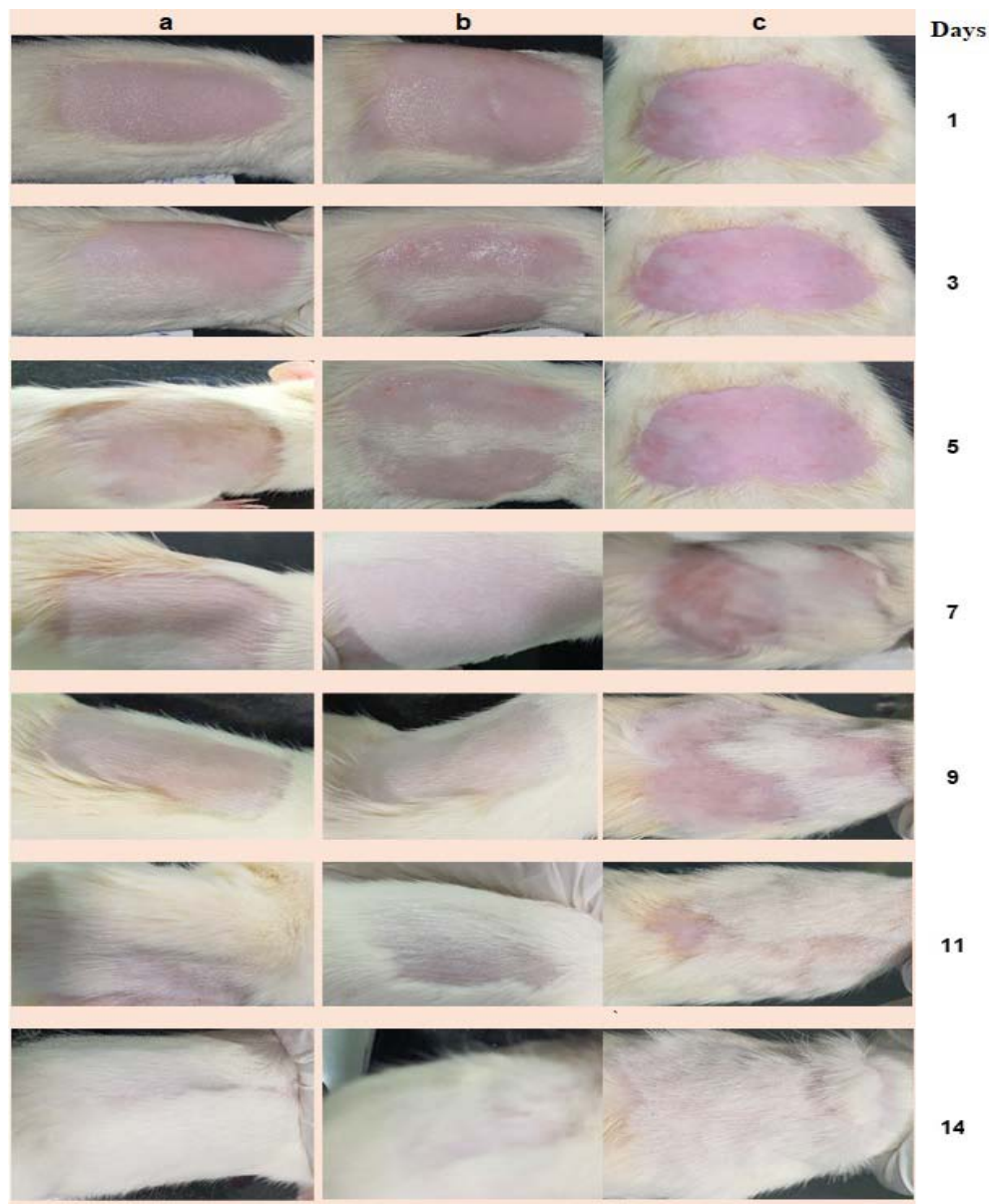

Fig. 14: Images of animal's rates during $14 \mathrm{~d}$ of applied formulations: (a) Optimized VCZ in situ film, (b) Placebo polymeric film, and (c) Negative control

\section{In vivo antifungal activity}

In vivo rats' skin study was performed to confirm the safety of optimized VCZ in situ polymeric film spray formulation. Fig. 15 depicts the skin after inducing the fungal infection for all groups. The infected rats were observed daily for signs of infection. However, On the third day, in all the animals, the inoculation of Candida albicans suspension was observed. The first indications of infection were detected in the form of redness on the skin. It became more evident on the six days in the form of scaling and well-defined redness on the skin. Itching and redness at the infection site were observed in the treatment group (b) after the treatment. Shedding of infected skin scales with the appearance of light pink colored skin was also seen after $14 \mathrm{~d}$ of treatment with a satisfactory growth of the hair at the infection site. Table 15 compares the symptoms of fungal infection during the treatment with various formulations (optimized VCZ in situ polymeric 
film, placebo formulation, and negative control). The obtained results of in vivo pharmacokinetics and the microbiological experiments show the improvement in pharmacokinetics activity with reduced symptoms of Candida albicans by the developed in situ polymeric film spray formulation. This might be because of the enhanced adhesion of the drug on the external skin layer.

Table 15: Mean scores after $14 \mathrm{~d}$ of treatment for in vivo animal study of the VCZ optimized, placebo formulation, and Negative control

\begin{tabular}{|c|c|c|c|c|c|c|c|c|c|c|c|c|c|c|c|}
\hline \multirow[t]{3}{*}{ Parameters } & \multicolumn{15}{|c|}{ Group/days } \\
\hline & \multicolumn{5}{|c|}{ G1/d } & \multicolumn{5}{|c|}{ G2/d } & \multicolumn{5}{|c|}{ G3/d } \\
\hline & 1 & 3 & 7 & 10 & 14 & 1 & 3 & 7 & 10 & 14 & 1 & 3 & 7 & 10 & 14 \\
\hline Erythema & 0 & 0 & 2 & 1 & 1 & 0 & 0 & 1 & 1 & 0 & 0 & 0 & 1 & 1 & 0 \\
\hline Edema & 0 & 1 & 1 & 0 & 1 & 0 & 0 & 1 & 1 & 0 & 0 & 0 & 1 & 0 & 0 \\
\hline Papule & 0 & 0 & 1 & 0 & 0 & 0 & 0 & 1 & 0 & 0 & 0 & 0 & 0 & 2 & 2 \\
\hline Flakiness & 0 & 0 & 1 & 1 & 0 & 0 & 0 & 0 & 1 & 0 & 0 & 0 & 1 & 3 & 2 \\
\hline Dryness & 0 & 1 & 4 & 4 & 1 & 0 & 0 & 1 & 1 & 0 & 1 & 2 & 4 & 3 & 3 \\
\hline
\end{tabular}

G1: Placebo in situ formulations, G2: Optimized in situ formulations, G3: Negative control. 0: no signs of infection; 1: slight redness on the skin; 2: marked redness with scaly areas; 3: redness on large regions, incrustation, and development of nodules; 4 : indicating the severe redness, scaly spaces.
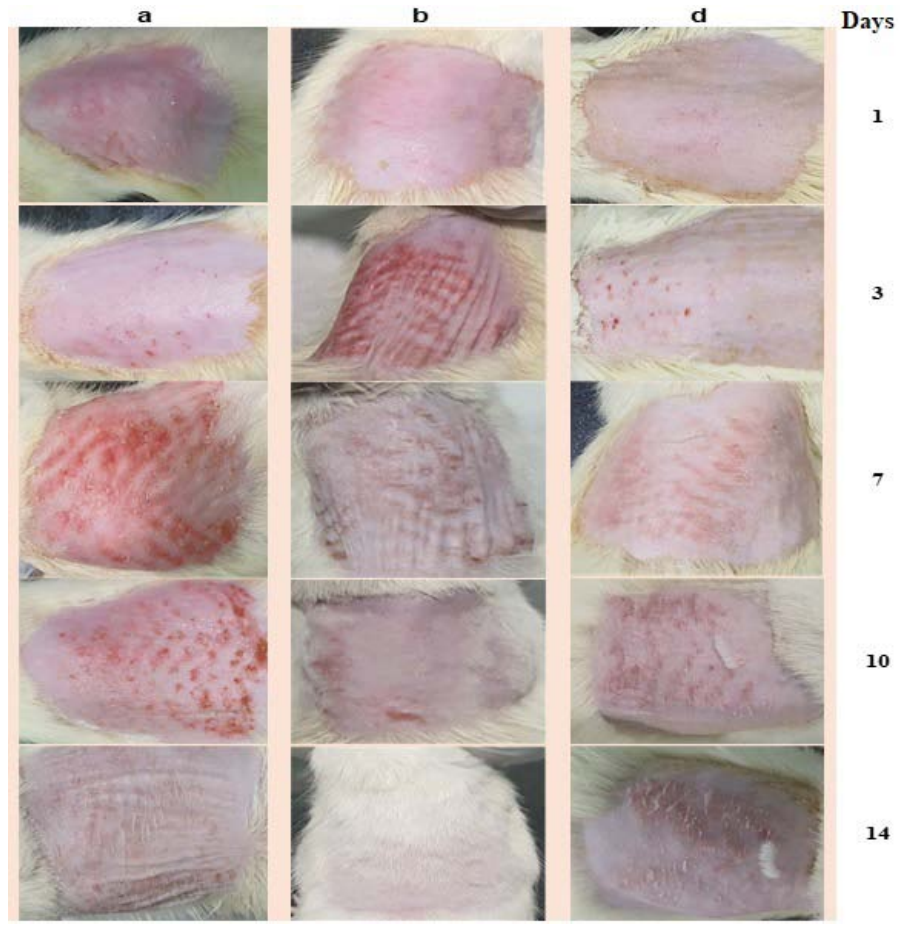

Fig. 16: Diagrammatic, images report of fungal infection rates during $14 \mathrm{~d}$ of treatment: (a) VCZ in situ films (b) Placebo formulation (c) Negative control

\section{Histopathological studies}

Skin specimens were investigated to evaluate cutaneous condition potential of optimized VCZ in situ polymeric film, placebo in situ polymeric film, and untreated rat skin (negative control). Histopathological examination for treated rat skin by VCZ in situ polymeric film was observed normalized epidermis and provisional matrix, well-defined collagen, and Elastin layer or well-defined dermis with capillaries. There was a prominent boundary between the provisional matrix and mature dermis; microvasculature was appeared and shown in (fig. 16\{A1\}).

Ratskin treated by placebo in situ polymeric film was observed; in the epidermal layer, the photograph showed a decrease in the size of the sebaceous gland, with a flattening thick, horny epidermal layer, and hair follicles with a narrow lumen. Dermis fibers and hypodermis were poorly identified with collagen, elastin fibers. Collagen fibers lost their details and were combined with a homogenous, hyalinization appearance. Microvasculature is found in a provisional matrix, as depicted in fig. $16\{\mathrm{~A} 2\}$.

The skin was seen with photomicrographs of the negative control. The picture showed hyperkeratosis in the epidermal layer with a flattening thick horny layer, a decline in sebaceous gland size, and hair follicles with a narrow lumen. Collagen, elastin fibers of the dermis and hypodermis of the showed poor-defined. The collagen fibers lost their details and appeared fused with a homogeneous, hyalinization appearance was found. Microvasculature found in the provisional matrix indicated by an arrow, as shown in fig. $16\{\mathrm{~A} 3\}$.

Histopathological studies have shown that VCZ, a topical in situ polymer film spray, is not irritating or affecting the skin. No liaisons were observed; neither was any significant change in the skin or any break in the epithelium's length. No ulceration was seen.

Moreover, the results of significant organ histopathology examinations of liver and kidney fig. $16\{\mathrm{~B}$ and $\mathrm{C}\}$ revealed no damaging effects from repeated skin exposure to any of the groups. Insignificant alterations were detected as a result of the findings. This could be related to the reasons that only a tiny amount of the drug is absorbed into the blood circulation upon topical treatment of VCZ from an in situ polymeric spray solution or a placebo formulation. Hence, VCZ topical in situ polymeric film sprays may be considered a safe option for the skin. 

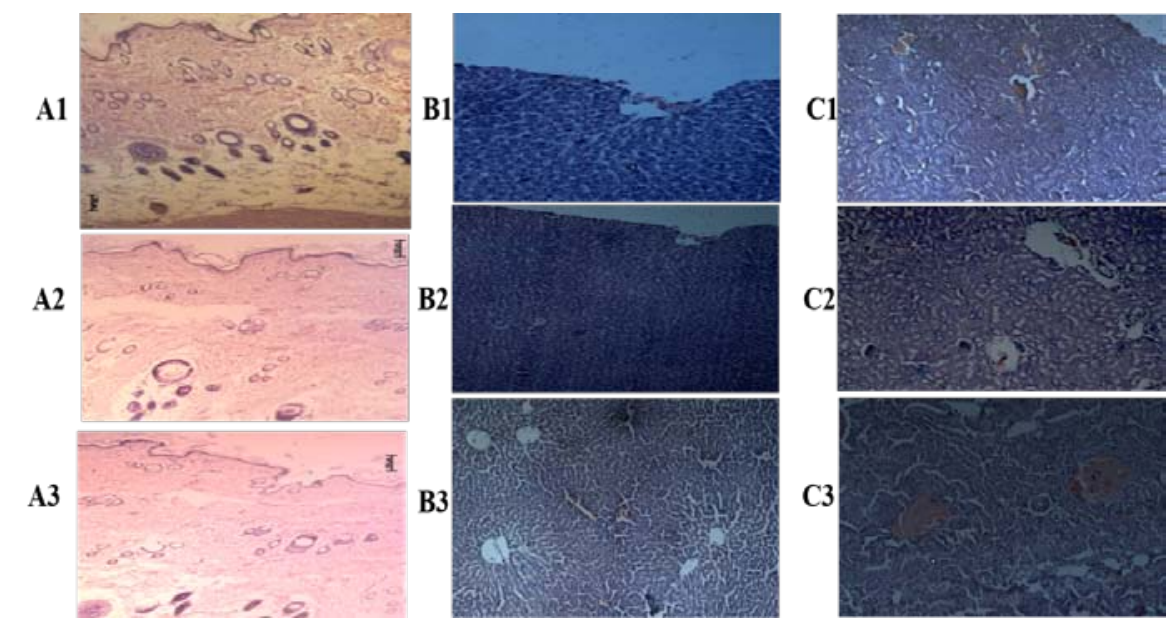

Fig. 16: Representative histopathic sections of different organs with repetitive topical administration of the VCZ in situ polymeric film spray in a 14-day cutaneous acute toxicity. (A) Skin (B) Liver, (C) Kidney (1) VCZ in situ polymeric film, (2), Placebo formulation, (3) Negative control

\section{Stability studies}

The results of the stability study of the optimized VCZ in situ polymeric film formulation (F-5) after one month, two months, and six months at different storage conditions (in the refrigerator $(4 \pm 2$ ${ }^{\circ} \mathrm{C}$ ), room temperature $\left(25 \pm 2{ }^{\circ} \mathrm{C} / 60 \pm 5 \% \mathrm{RH}\right)$ and humidity control chamber $\left.\left(45 \pm 2{ }^{\circ} \mathrm{C} / 75 \pm 5 \% \mathrm{RH}\right)\right)$ are shown in table 16 . No noticeable/significant change in the drying time, transparency, stickiness, viscosity, the volume of solution delivered by actuation, density, spray angle, spray pattern, folding endurance, thickness, tensile strength, elongation at break, $\mathrm{pH}$ study, and Cumulative Drug Release (CDR) \% of the optimized formulation was perceived during the study period; indicating exhibit of good stability by optimized VCZ in situ polymeric film formulation during the study period.

Table 16: Storage stability data of the optimized formulation batch F5

\begin{tabular}{|c|c|c|c|c|c|c|c|c|c|c|}
\hline \multirow{2}{*}{$\begin{array}{l}\text { S. } \\
\text { No. }\end{array}$} & \multirow[t]{2}{*}{ Parameters } & \multicolumn{3}{|l|}{ At $4^{\circ} \mathrm{C}$} & \multicolumn{3}{|l|}{ At $25 \pm 2{ }^{\circ} \mathrm{C}$} & \multicolumn{3}{|l|}{ At $45 \pm 2{ }^{\circ} \mathrm{C}$} \\
\hline & & $2 \mathrm{mo}$ & $4 \mathrm{mo}$ & $6 \mathrm{mo}$ & $2 \mathrm{mo}$ & $4 \mathrm{mo}$ & $6 \mathrm{mo}$ & $2 \mathrm{mo}$ & $4 \mathrm{mo}$ & $6 \mathrm{mo}$ \\
\hline 1 & $\mathrm{DT}^{*}(\mathrm{sec})$ & $34 \pm 0.06$ & $34 \pm 0.04$ & $34 \pm 0.01$ & $35 \pm 0.06$ & $35 \pm 0.04$ & $33 \pm 0.01$ & $36 \pm 0.03$ & $33 \pm 0.07$ & $35 \pm 0.08$ \\
\hline 2 & Transparency & +++ & +++ & +++ & +++ & +++ & +++ & +++ & +++ & +++ \\
\hline 3 & $\begin{array}{l}\text { Stickiness } \\
\text { (Yes/No) }\end{array}$ & No & No & No & No & No & No & No & No & No \\
\hline 4 & Viscosity (cps) & $0.13 \pm 0.04$ & $0.13 \pm 0.8$ & $0.12 \pm 0.3$ & $0.13 \pm 0.04$ & $0.13 \pm 0.8$ & $0.12 \pm 0.3$ & $0.13 \pm 0.07$ & $0.12 \pm 0.2$ & $0.12 \pm 0.6$ \\
\hline 5 & $\begin{array}{l}\text { delivered by } \\
\text { actuation }(\mathrm{ml})\end{array}$ & $0.289 \pm 0.021$ & $0.291 \pm 0.022$ & $0.292 \pm 0.021$ & $0.288 \pm 0.03$ & $0.286 \pm 0.03$ & $0.286 \pm 0.02$ & $0.280 \pm 0.04$ & $0.281 \pm 0.08$ & $0.282 \pm 0.03$ \\
\hline 6 & $\begin{array}{l}\text { Density } \\
\text { (gm/ml) }\end{array}$ & $0.691 \pm 0.01$ & $0.686 \pm 0.03$ & $0.685 \pm 0.02$ & $0.688 \pm 0.01$ & $0.689 \pm 0.03$ & $0.683 \pm 0.02$ & $0.685 \pm 0.04$ & $0.689 \pm 0.02$ & $0.683 \pm 0.05$ \\
\hline 7 & Spray angle & $81.63 \pm 0.07$ & $81.12 \pm 0.04$ & $80.72 \pm 0.04$ & $80.05 \pm 0.07$ & $81.25 \pm 0.04$ & $81.50 \pm 0.04$ & $81.21 \pm 0.08$ & $80.31 \pm 0.03$ & $80.42 \pm 0.02$ \\
\hline 8 & Spray pattern & $\begin{array}{l}\text { spherical } \\
\text { anduniform }\end{array}$ & $\begin{array}{l}\text { spherical and } \\
\text { uniform }\end{array}$ & $\begin{array}{l}\text { spherical and } \\
\text { uniform }\end{array}$ & $\begin{array}{l}\text { spherical } \\
\text { anduniform }\end{array}$ & $\begin{array}{l}\text { spherical } \\
\text { and } \\
\text { uniform }\end{array}$ & $\begin{array}{l}\text { spherical } \\
\text { and } \\
\text { uniform }\end{array}$ & $\begin{array}{l}\text { spherical } \\
\text { anduniform }\end{array}$ & $\begin{array}{l}\text { spherical } \\
\text { and } \\
\text { uniform }\end{array}$ & $\begin{array}{l}\text { spherical } \\
\text { and } \\
\text { uniform }\end{array}$ \\
\hline 9 & $\begin{array}{l}\text { Folding } \\
\text { Endurance }\end{array}$ & Satisfactory & Satisfactory & Satisfactory & Satisfactory & Satisfactory & Satisfactory & Satisfactory & Satisfactory & Satisfactory \\
\hline 10 & Thickness & $0.085 \pm 0.01$ & $0.084 \pm 0.06$ & $0.084 \pm 0.10$ & $0.083 \pm 0.08$ & $0.084 \pm 0.03$ & $0.083 \pm 0.09$ & $0.083 \pm 0.07$ & $0.084 \pm 0.03$ & $0.083 \pm 0.09$ \\
\hline 11 & $\begin{array}{l}\text { Tensile strength } \\
\left(\mathrm{Kg} / \mathrm{cm}^{2}\right)\end{array}$ & $0.165 \pm 0.02$ & $0.163 \pm 0.05$ & $0.160 \pm 0.04$ & $0.162 \pm 0.09$ & $0.164 \pm 0.07$ & $0.161 \pm 0.02$ & $0.171 \pm 0.07$ & $0.168 \pm 0.03$ & $0.161 \pm 0.02$ \\
\hline 12 & $\begin{array}{l}\text { Elongation at } \\
\text { break \% }\end{array}$ & $9.57 \pm 0.02$ & $9.55 \pm 0.07$ & $9.53 \pm 0.03$ & $9.51 \pm 0.08$ & $9.59 \pm 0.03$ & $9.52 \pm 0.07$ & $9.62 \pm 0.03$ & $9.57 \pm 0.02$ & $9.56 \pm 0.07$ \\
\hline 13 & $\begin{array}{l}\text { Water Vapor } \\
\text { Permeability (g- } \\
\mathrm{mm} / \mathrm{kpa}-\mathrm{m}^{2} \text { ) }\end{array}$ & $0.0025 \pm 0.2$ & $0.0024 \pm 0.3$ & $0.0024 \pm 0.4$ & $0.0023 \pm 0.4$ & $0.0025 \pm 0.5$ & $0.0022 \pm 0.2$ & $0.0025 \pm 0.4$ & $0.0025 \pm 0.5$ & $0.0024 \pm 0.6$ \\
\hline 14 & pH study & 7.11 & 7.10 & 7.10 & 7.10 & 7.10 & 7.10 & 7.09 & 7.10 & 7.10 \\
\hline 15 & $\begin{array}{l}\text { Moisture } \\
\text { content (\%) }\end{array}$ & $1.5 \pm 0.12$ & $1.4 \pm 0.11$ & $1.5 \pm 0.14$ & $1.5 \pm 0.10$ & $1.5 \pm 0.14$ & $1.4 \pm 0.12$ & $1.3 \pm 0.14$ & $1.3 \pm 0.13$ & $1.2 \pm 0.10$ \\
\hline 16 & CDR (\%) & 99.22 & 98.47 & 97.24 & 99.42 & 97.82 & 97.12 & 98.45 & 98.21 & 97.74 \\
\hline
\end{tabular}

Mean of 6 reading \pm SD

\section{CONCLUSION}

This study concludes that VCZ can form a topical in situ filmforming development using a mixture of ERS and Sorbitol as plasticizers using the response surface method. The optimized formulation demonstrated antifungal activity against Candida Albicans epidermidis in culture and animal studies. The impact of formulating variables on product properties can be easily predicted using a $3^{2}$-level factorial experimental design and quadratic mathematical equations developed. According to the specifications of the procedures, such as DT\%, Viscosity, FT-IR, DSC, XRD, SEM, Rheological study, In vitro release study (using cellophane membrane), Ex-vivo drug diffusion, the kinetics of drug release (Zero order, First order, and Higuchi Model), In vitro antifungal activity, In vivo studies (Skin irritation, in vivo antifungal activity and histopathology test), and Stability Studies. The best batch of topical VCZ in situ film-forming would be $22 \%$ ERS and 4\% Sorbitol. 


\section{ABBREVIATIONS}

\begin{tabular}{ll}
\hline Abbreviation & Explanation \\
\hline$V C Z$ & Voriconazole \\
$E R S$ & Eudragite RS 100 \\
$D O E$ & Designed of experiments \\
$D T$ & Dry time \\
$D S C$ & Differentials scanning calorimetry \\
$W V P$ & Water vapor permeability \\
$X R D$ & X-ray diffractometry \\
$S E M$ & Scanning electron microscopy \\
$F T-I R$ & Fourier transform infrared \\
$D M S O$ & Dimethyl sulfoxide \\
\hline
\end{tabular}

\section{ACKNOWLEDGEMENT}

The researchers profoundly put their words of gratefulness and thankfulness for the JSS Academy of Higher Education and Research, Mysuru, 570015, Karnataka, India, for their significant facilities and constant support for carrying out the current study.

\section{ETHICAL APPROVAL}

All experimental regulations were directed and applied based on the study's ethical procedures approved by the Institutional Animal Ethical Committee recognized, JSS College of Pharmacy, JSS Academy of Higher Education and Research, Mysuru, India.

\section{FUNDING}

Nil

\section{AUTHORS CONTRIBUTIONS}

All the authors have contributed equally.

\section{CONFLICT OF INTERESTS}

The authors state and confirm that there is no dispute or conflict of interest among them.

\section{REFERENCES}

1. Achkar JM, Fries BC. Candida infections of the genitourinary tract. Clinical Microbiology Reviews. 2010;23(2):253-73.

2. Jackson BE, Wilhelmus KR, Mitchell BM. Genetically regulated filamentation contributes to Candida albicans virulence during corneal infection. Microbial Pathogenesis. 2007;42(2-3):88-93.

3. Tran TTD, Tran PHL. Controlled release film forming systems in drug delivery: the potential for efficient drug delivery. Pharmaceutics. 2019 Jun 20;11(6):290.

4. Kim Y, Beck Broichsitter M, Banga AK. Design and evaluation of a poly(Lactide-co-glycolide)-based in situ film-forming system for topical delivery of trolamine salicylate. Pharmaceutics. 2019;11(8).

5. Frederiksen K, Guy RH, Petersson K. The potential of polymeric film-forming systems as sustained delivery platforms for topical drugs. Expert Opinion on Drug Delivery. 2016 Mar 3;13(3):349-60.

6. Silva-Alvarez AF, Ferreira MP, Vicentini FTMC, Pedrazzi V, de Freitas 0 . A new approach to ex vivo permeation studies in insitu film-forming systems. AAPS PharmSciTech. 2020 Oct 7;21(7):257.

7. Felton LA. Mechanisms of polymeric film formation. International Journal of Pharmaceutics. 2013;457(2):423-7.

8. Umar AK, Butarbutar M, Sriwidodo S, Wathoni N. Film-forming sprays for topical drug delivery. Drug Design, Development and Therapy. 2020;14:2909-25.

9. Psimadas D, Georgoulias P, Valotassiou V, Loudos G. Impact of antinucleants on transdermal delivery of testosterone from a spray. J Pharmaceutical Sciences. 2012;101(7):2271-80.

10. Riyaz Ali M. Osmani PKK. $3^{2}$ Full factorial design for development and characterization of nanosponges based intravaginal in situ gelling system for vulvovaginal candidiasis. RSC Advances. 2016;11(23).

11. Fukuda IM, Pinto CFF, Moreira CDS, Saviano AM, Lourenço FR. Design of experiments (DoE) applied to pharmaceutical and analytical quality by design (QbD). Brazilian Journal of Pharmaceutical Sciences. 2018;54(Special Issue):1-16.
12. Nabil Abdullah, Amit B Patil. Application of DoE in polymers screening and optimization of in situ topical film-forming solution for spray formulation. International Journal of Research in Pharmaceutical Sciences. 2020;11(Special Issue 4):2499-515.

13. Frederiksen K, Guy RH, Petersson K. Formulation considerations in the design of topical, polymeric film-forming systems for sustained drug delivery to the skin. European Journal of Pharmaceutics and Biopharmaceutics. 2015;91:9-15.

14. Ranade S, Bajaj A, Londhe V, Babul N, Kao D. Fabrication of topical metered dose film forming sprays for pain management. European J Pharmaceutical Sciences. 2017;100:132-41.

15. Das T, Venkatesh MP, Pramod Kumar TM, Koland M. SLN based alendronate in situ gel as an implantable drug delivery systemA full factorial design approach. Journal of Drug Delivery Science and Technology. 2020;55:1-26.

16. Pratiwi L, Sari R, Apridamayanti P. Original article design and characterization of nanospray with self-nanoemulsifying drug delivery system using sinergistic combination of melastoma malabathricum L. Fraction and Gentamicin. 2021;13(2)

17. Zurdo Schroeder I, Franke P, Schaefer UF, Lehr CM. Development and characterization of film forming polymeric solutions for skin drug delivery. European Journal of Pharmaceutics and Biopharmaceutics. 2007;65(1):111-21.

18. Bansal G, Garg VK, Jha KK. Formulation and evaluation of polymeric thin films of zolmitriptan. Journal of Pharmacy Research. 2018;12(2):168.

19. Anter HM, Hashim IIA, Awadin W, Meshali MM. Novel antiinflammatory film as a delivery system for the external medication with bioactive phytochemical "Apocynin." Drug Design, Development and Therapy. 2018;12(November):2981-3001.

20. Anter HM, Hashim IIA, Awadin W, Meshali MM. Novel antiinflammatory film as a delivery system for the external medication with bioactive phytochemical "Apocynin." Drug Design, Development and Therapy. 2018;12:2981-3001.

21. Edwards A, Qi S, Liu F, Brown MB, McAuley WJ. Rationalising polymer selection for supersaturated film forming systems produced by an aerosol spray for the transdermal delivery of methylphenidate. European Journal of Pharmaceutics and Biopharmaceutics. 2017;114:164-74.

22. Zhang L, Alfano J, Race D, Dave RN. Zero-order release of poorly water-soluble drug from polymeric films made via aqueous slurry casting. European Journal of Pharmaceutical Sciences. 2018;117(Jan):245-54.

23. Mundada A, Satturwar P, Fulzele S, Joshi S, Dorle A. Characterization and evaluation of novel film forming polymer for drug delivery. Iranian Journal of Pharmaceutical Research. 2011;10(1):35-42.

24. Jantrawut $\mathrm{P}$, Chaiwarit $\mathrm{T}$, Jantanasakulwong $\mathrm{K}$, Brachais $\mathrm{CH}$, Chambin 0 . Effect of plasticizer type on tensile property and in vitro indomethacin release of thin films based on low-methoxyl pectin. Polymers. 2017;9(7).

25. Huang J, Deng Y, Ren J, Chen G, Wang G, Wang F. Novel in situ forming hydrogel based on xanthan and chitosan re-gelifying in liquids for local drug delivery. Carbohydrate Polymers [Internet]. 2018;186(Jan):54-63.

26. Padula C, Nicoli S, Pescina S, Santi P. Thin polymeric films for the topical delivery of propranolol. Colloids and Surfaces B: Biointerfaces. 2019;174:582-6.

27. Vij NN, Saudagar RB. Formulation, development and evaluation of film-forming gel for prolonged dermal delivery of terbinafine hydrochloride. International Journal of Pharma Sciences and Research (IJPSR). 2014;5(9):537-54.

28. Ammar HO, Ghorab M, Mahmoud AA, Makram TS, Ghoneim AM. Rapid pain relief using transdermal film forming polymeric solution of ketorolac. Pharmaceutical Development and Technology. 2013;18(5):1005-16.

29. Barot BS, Parejiya PB, Patel HK, Gohel MC, Shelat PK. Microemulsion-based gel of terbinafine for the treatment of onychomycosis: Optimization of formulation using D-optimal design. AAPS PharmSciTech. 2012;13(1):184-92.

30. Elnaggar YSR, Talaat SM, Bahey-El-Din M, Abdallah OY. Novel lecithin-integrated liquid crystalline nanogels for enhanced cutaneous targeting of terconazole: Development, in vitro and in vivo studies. International Journal of Nanomedicine. 2016;11:5531-47. 
31. Campus B, Vishwavidyalaya GK. Original article effect of polymeric blend on ex-vivo permeation studies of aceclofenac loaded film forming gel. 2021;13(4):1-6.

32. Patel DP, Setty CM, Mistry GN, Patel SL, Patel TJ, Mistry PC. Development and evaluation of ethyl cellulose-based transdermal films of furosemide for improved in vitro skin permeation. AAPS PharmSciTech. 2009;10(2):437-42.

33. Plga-lpt-ck P, Kumar JR. Development and antifugal activity of itraconazole loaded ethosomal gel in rat animal model. Journal of Pharmaceutical Sciences and Research. 2019;(Aug):5-11.

34. Paradkar M, Thakkar V, Soni T, Gandhi T, Gohel M. Formulation and evaluation of clotrimazole transdermal spray. Drug Development and Industrial Pharmacy. 2015;41(10):1718-25.

35. Kelidari HR, Babaei R, Nabili M, Shokohi T, Saeedi M, Gholami S, et al. Improved delivery of voriconazole to Aspergillus fumigatus through solid lipid nanoparticles as an effective carrier. Colloids and Surfaces A: Physicochemical and Engineering Aspects. 2018;558(Aug):338-42.

36. Hussain A, Samad A, Singh SK, Ahsan MN, Haque MW, Faruk A. Nanoemulsion gel-based topical delivery of an antifungal drug: In vitro activity and in vivo evaluation. Drug Delivery. 2016;23(2):652-67.

37. Elmataeeshy ME, Sokar MS, Bahey-El-Din M, Shaker DS. Enhanced transdermal permeability of Terbinafine through novel nanoemulgel formulation; Development, in vitro and in vivo characterization. Future Journal of Pharmaceutical Sciences. 2018;4(1):18-28.
38. Bajaj A, Malhotra G, Madan M, Amrutiya N, Bakshi A. A novel metered dose transdermal spray formulation for oxybutynin. Indian Journal of Pharmaceutical Sciences. 2008;70(6):733.

39. Geh KJ, Stelzl A, Gröne A, Wagner L, Forster B, Winter G. Development of a sprayable hydrogel formulation for the skin application of therapeutic antibodies. European Journal of Pharmaceutics and Biopharmaceutics. 2019;142(June 2019):123-32.

40. Rutthapol Sritharadol, Titpawan Nakpheng, Paul Wan Sia Heng, Teerapol Srichana. "Development of a topical mupirocin spray for antibacterial and wound-healing applications," Drug Development and Industrial Pharmacy. 2017;43:1715-28.

41. Gohel MC, Nagori SA. Fabrication of modified transport fluconazole transdermal spray containing ethyl cellulose and eudragit ${ }^{\circledR}$ RS100 as film formers. AAPS PharmSciTech. 2009;10(2):684-91.

42. Amanda F Silva, Alvarez, Maíra P Ferreira, Fabiana TMC, V Pedrazzi, o de Freitas Vicentini, Vinicius Pedrazzi, Osvaldo de Freitas. A new approach to ex vivo permeation studies in in-situ film-forming systems. AAPS PharmSciTech 2020;21:257.

43. A Bakshi, A Bajaj, G Malhotra, M Madan, N Amrutiyai. A novel metered dose transdermal spray formulation for oxybutynin. Indian J Pharm Sci. 2008;70:733.

44. Dhaval P Patel. Development and evaluation of ethyl cellulosebased transdermal films of furosemide for improved in vitro skin permeation. AAPS PharmSciTech. 2009;10:437-42. 